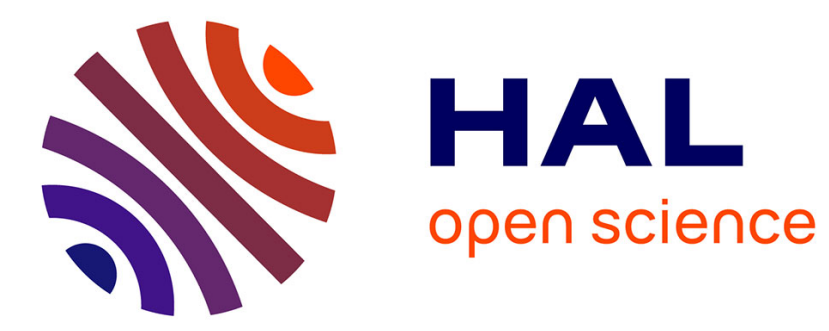

\title{
Crossing the rural-urban boundary in hydrological modelling: How do conceptual rainfall-runoff models handle the specificities of urbanized catchments?
}

\author{
Mohamed Saadi, Ludovic Oudin, Pierre Ribstein
}

\section{To cite this version:}

Mohamed Saadi, Ludovic Oudin, Pierre Ribstein. Crossing the rural-urban boundary in hydrological modelling: How do conceptual rainfall-runoff models handle the specificities of urbanized catchments? Hydrological Processes, 2020, 34 (15), pp.3331-3346. 10.1002/hyp.13808 . hal-03060541

\section{HAL Id: hal-03060541 \\ https://hal.sorbonne-universite.fr/hal-03060541}

Submitted on 14 Dec 2020

HAL is a multi-disciplinary open access archive for the deposit and dissemination of scientific research documents, whether they are published or not. The documents may come from teaching and research institutions in France or abroad, or from public or private research centers.
L'archive ouverte pluridisciplinaire HAL, est destinée au dépôt et à la diffusion de documents scientifiques de niveau recherche, publiés ou non, émanant des établissements d'enseignement et de recherche français ou étrangers, des laboratoires publics ou privés. 


\title{
Crossing the rural-urban boundary in hydrological modeling: How do conceptual rainfall-runoff models handle the specificities of urbanized catchments?
}

\author{
Mohamed Saadi*, Ludovic Oudin, Pierre Ribstein \\ Sorbonne Université, CNRS, EPHE, UMR METIS, F-75000, Paris, France. \\ Published in Hydrological Processes, doi: 10.1002/hyp.13808. \\ *Corresponding author : mohamed.saadi@sorbonne-universite.fr
}

\begin{abstract}
Landscape differences induced by urbanization have prompted hydrologists to define a fuzzy boundary between rural and urban-specific hydrological models. We addressed the validity of establishing this boundary, by testing two rural models on a large sample of 175 French and United States (US) urbanized catchments, and their 175 rural neighbors. The impact of urbanization on the hydrological behavior was checked using four metrics. Using a split-sample test, we have compared the performances, parameter distributions and internal fluxes of GR4H and IHACRES, two conceptual and continuous models running at the hourly time step. Both model structures are based on soil moisture accounting reservoirs (infiltration, runoff, and actual evapotranspiration) and quick flow/slow flow routing components, with no consideration of any specific feature related to urbanization. Results showed: (1) Except for the ratio of streamflow flashiness to precipitation flashiness, the range of hydrological signature metrics in rural catchments encompassed the specificities of urbanized ones. Overall, the urbanized catchments showed higher ratios of mean streamflow to mean precipitation (median values: 0.39 vs. 0.27 ) and streamflow flashiness to precipitation flashiness ( 0.13 vs. 0.03 ), besides lower baseflow index ( 0.42 vs. 0.62 ) and shorter characteristic response time ( 3 vs. $14 \mathrm{~h}$ ). (2) The performances of GR4H revealed no significant distinction between rural and urbanized catchments in terms of KlingGupta Efficiency ( $K G E$ ), whereas IHACRES better simulated urbanized catchments, especially during summer. (3) With respect to differences in urbanization level, the GR4H and IHACRES parameters showed different distributions. The differences in parameters were consistent with the differences in hydrological behavior, which is promising for a model-based assessment of the impact of urbanization. (4) The models agreed less in reproducing the internal fluxes over the urbanized catchments than over the rural ones. These results demonstrate the flexibility of conceptual models to handle the specificities of urbanized catchments.
\end{abstract}




\section{Introduction}

\subsection{From contrasting landscapes to contrasting hydrological modeling practices}

One can easily identify the differences between a "rural" and an "urbanized" landscape: green forests, season-colored crops, and vacant soil-colored lands are clearly distinguishable from areas where paved roads and gray buildings predominate. Population density is the first driver for such landscape discrepancies (Chen, Chuang, and Cheng, 2014; Martin, Kelleher, and Wagener, 2012): As the population that occupies the defined area increases, land conversion takes place to accommodate for the increasing population needs. From a hydrological standpoint, this land conversion causes a substantial increase in the total impervious area (TIA) of the catchment, which impacts the hydrological processes by specifically emphasizing high flows and altering low flows (e.g., DeWalle et al., 2000; Fletcher, Andrieu, and Hamel, 2013; Salvadore, Bronders, and Batelaan, 2015; Oudin et al., 2018).

These differences in hydrological behaviors between rural and urbanized areas have led hydrologists to develop specific modeling tools for urban catchments. Notwithstanding the existence of these differences, we argue that they are potentially not more important than the ones existing between two distinct rural areas or two distinct urban areas. Moreover, the conceptual tools and physically-based equations used in representing the hydrological processes present many similarities for both types of area (Salvadore, Bronders, and Batelaan, 2015). This was also pointed out by Fletcher, Andrieu, and Hamel (2013), who stated that: "Despite its particularity, urban hydrology is not that different from natural hydrology". The dichotomous approach consisting in selecting rural or urban-specific hydrological models is questionable. From an operational standpoint, this dichotomy leads to complicated choices for catchments with mixed urban/rural landscapes. In this context, a continuous modeling approach would be preferable to the dichotomous approach.

Rural conceptual hydrological models have been widely tested in large-sample studies (Addor et al., 2020; Gupta et al., 2014) and proved to be particularly flexible in the simulation of a large panoply of hydrological behaviors through changes in their parameters. However, these studies have often discarded (or not sufficiently emphasized) the catchments that were characterized by a high proportion of urban cover (Addor et al., 2017; Ficchì, Perrin, and Andréassian, 2019; Esse et al., 2013), maintaining an invisible and fuzzy rural-urban boundary in hydrological practices.

\subsection{Scope of the study}

In this paper, we question the existence of such a boundary, addressing two related issues:

1. Whether urbanized and rural catchments clearly exhibit different hydrological behaviors and whether these differences are larger than the ones among rural catchments. We focus on four aspects of the hydrological behavior: (i) how much of precipitation is converted into streamflow; (ii) how important is the baseflow component; (iii) what is the lag time between precipitation and runoff; and (iv) what is the ability of the catchment to damp precipitation flashiness (Baker et al., 2004). 
2. Whether conceptual hydrological models are flexible enough to account for these different hydrological behaviors. These differences would impact the model performances, the parameter distributions, or the internal fluxes of the model.

These issues are addressed here through a comparative assessment across a large sample of urbanized and rural catchments. We collected a sample of 175 urbanized catchments (with a mean TIA above $10 \%$ over the period 1997-2017), which is far larger than the samples used in urbanized catchments studies (see the review by Salvadore, Bronders, and Batelaan (2015)). Benefiting from a paired-catchment framework (Martin, Kelleher, and Wagener, 2012; Van Loon et al., 2019; Zégre et al., 2010), we compared the average behavior of the urbanized catchments with geographically close rural catchments. Hence, an additional 175 rural catchments were used, for which mean $T I A$ was less than $5 \%$.

The study is presented as follows: in Section 2, we describe the catchment sample and the hydrological signatures that we used to investigate the differences in terms of hydrological behavior between the urbanized catchments and their rural neighbors. We also present the two rural models that were used to analyze the differences from a rural modeling standpoint. In Section 3, we show the assessment of both the hydrological signatures and the models. A discussion follows in Section 4, while Section 5 concludes with the main findings.

\section{Catchments and methodology}

\subsection{Sample description}

A large sample of catchments located in the United States (US) and France were collected. Working with an international sample of urbanized catchments is important from a hydrological perspective, as the differences in urban planning schemes between the two sides of the North Atlantic Ocean could have a significant impact on the water cycle.

The sample selection was made using four criteria:

1. Limited effect of snow, as the models we applied here do not take into account snow-melting processes.

2. Limited influence of dams. Although these impact river regimens (FitzHugh and Vogel, 2011), and are hence related to a particular type of human impact, we deemed this effect to be a particular case that required adequate streamflow naturalization techniques.

3. Recently available hourly precipitation and streamflow time series and daily temperature. We chose a minimum of 8 years of data availability between 1997 and 2017 as a requirement, for which complete precipitation and temperature data should be available, and streamflow data should be available for at least $70 \%$ of the recorded period. We considered that a minimum of 4 years for calibration was needed for an hourly model (Perrin et al., 2007).

4. The question of imperviousness threshold above which a catchment can be considered to be urbanized was not specifically analyzed in this study. On the basis of previous reviews (Arnold and Gibbons, 1996; Brabec, Schulte, and Richards, 2002; Brun and Band, 2000; Salvadore, Bronders, 


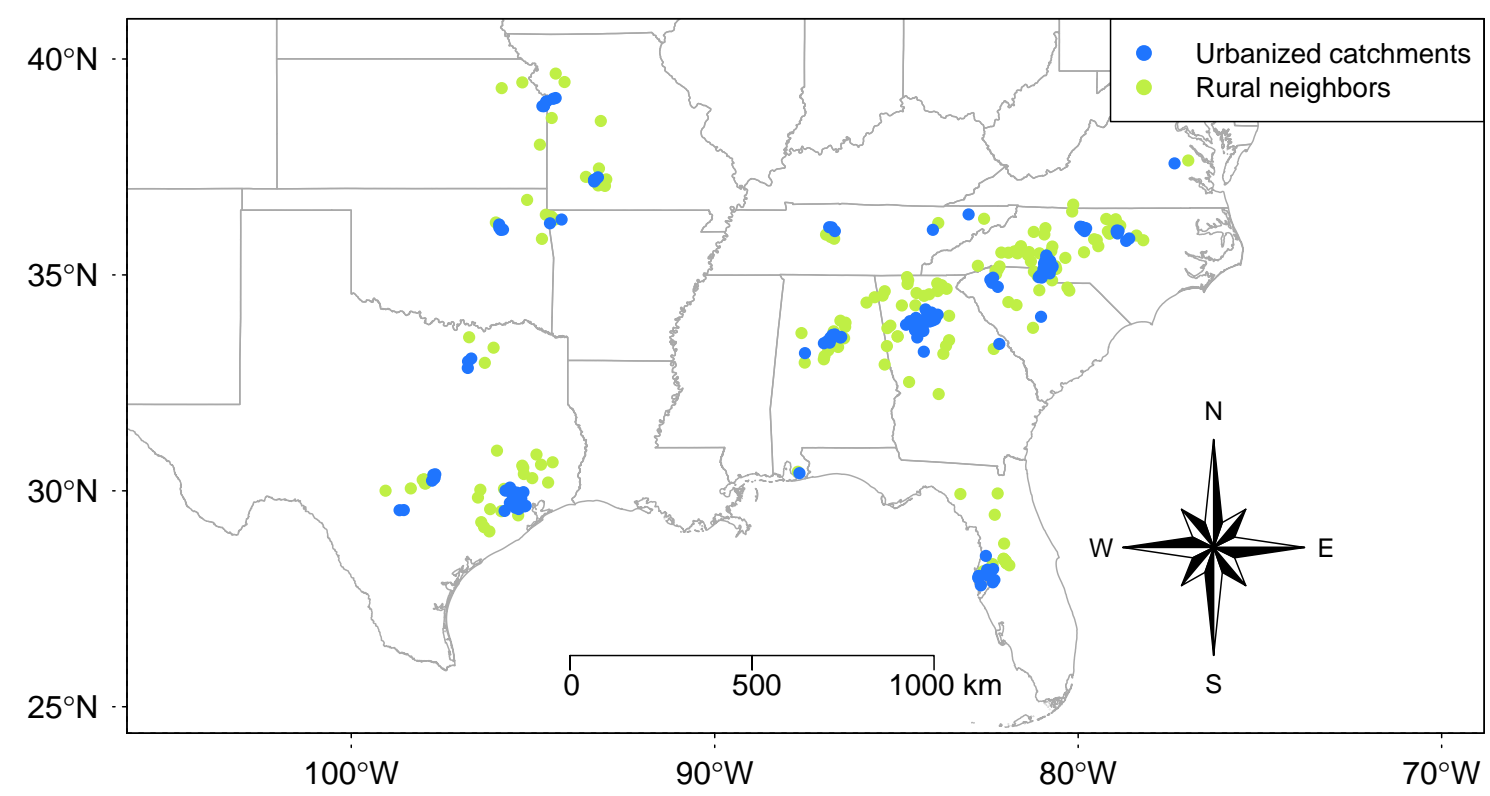

Figure 1. Location of the United States urbanized catchment sample (in blue) and their rural neighbors (in green). A dot represents the location of the catchment centroid.

and Batelaan, 2015), we considered a catchment as urbanized when its mean $T$ I A over the whole period was above $10 \%$. Other thresholds such as $15 \%$ and $20 \%$ were tested and did not significantly change the conclusions (not shown here).

For each urbanized catchment $X$, the selected rural neighbor catchment $Y$ was the closest rural catchment to $X$ (i.e., TIA of $Y$ is less than 5\%) in the sense of distance $d$, which was determined using the distances between the outlets ( $20 \%$ weight) and the centroids ( $80 \%$ weight) of the catchments $X$ and $Y$ (Lebecherel, Andréassian, and Perrin, 2013).

This selection yielded a final sample of 175 urbanized catchments, of which 156 are located in the US and the remaining 19 in France. Figure 1 shows the US urbanized catchments and their rural neighbors' location. Figure 2 shows the location of the French sample.

The US sample was selected from the GAGES-II database (Falcone, 2011), for which hourly streamflow time series were extracted from the gauges maintained by the US Geological Survey (USGS) using the dataRetrieval R package (Cicco et al., 2018). Hourly precipitation depths were extracted from the NCEP Stage IV product, available at a 4-km resolution using the geo kn i fe R package (Lin and Mitchell, 2005; Read et al., 2015). Daily temperature was extracted from the Daymet product available at a 1-km resolution (Thornton et al., 2016). To characterize the degree of imperviousness of the catchment, we used the National Land Cover Database (NLCD) produced by the Multi-Resolution Land Characteristics (MRLC) Consortium for the years 2001, 2006, 2011, and 2016 at a 30-m resolution (e.g., Homer et al., 2015).

The French sample was selected from the Banque HYDRO database, for which hourly streamflow time series were extracted using the hydro. eaufrance. fr platform (Leleu et al., 2014). Hourly precipitation depths were prepared using the COMEPHORE product provided by Météo France (Tabary et al., 2012), available at a 1-km resolution across France. Daily temperature was extracted from the 


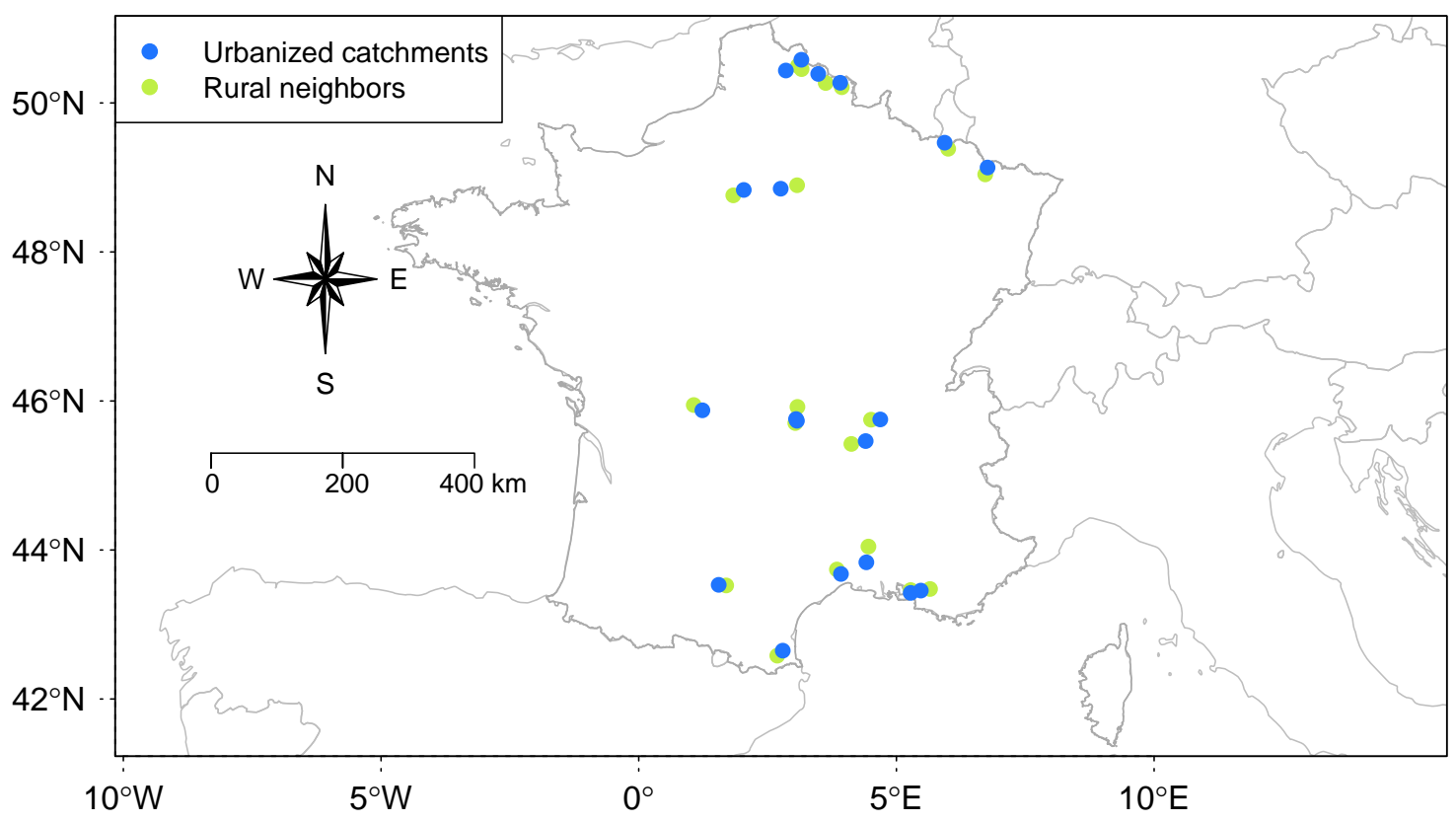

Figure 2. Location of the French urbanized catchment sample (in blue) and their rural neighbors (in green). A dot represents the location of the catchment centroid.

SAFRAN product available at an 8-km resolution, provided by Météo France (Vidal et al., 2010). The degree of imperviousness of the catchment was characterized using the Imperviousness Density layers produced by the Copernicus Land Monitoring Service, available for the years 2006, 2009, 2012, and 2015 at a 20-m resolution (Congedo et al., 2016).

For a given catchment, the mean $T I A$ was assessed by an arithmetic mean of the imperviousness values of catchment pixels. These values are percentages of sealed/developed surfaces estimated over every 30-m pixel in the US and 20-m pixel in France. After spatial aggregation, a linear extrapolation helped estimate the mean TIA for the years where land-use characterization was not available.

To estimate the potential evapotranspiration, we used a temperature-based formula (Oudin et al., 2005) to determine daily time series, followed by disaggregation using hourly extraterrestrial radiation to estimate hourly values.

The sizes of the urbanized catchments ranged between $1.1 \mathrm{~km}^{2}$ and $727 \mathrm{~km}^{2}$ with a median area of $47.7 \mathrm{~km}^{2}$, while their rural neighbors' sizes were between $2.4 \mathrm{~km}^{2}$ and $4580 \mathrm{~km}^{2}$ with a median area of $274 \mathrm{~km}^{2}$. The majority of US catchments used here are characterized by a humid subtropical climate (Cfa type in the Köppen-Geiger climate classification system; see Beck et al., 2018), whereas temperate oceanic and mediterranean types of climate characterize the French catchments. The mean precipitation depths for the urbanized/rural pairs of catchments were comparable (mean of $1190 \mathrm{~mm}$ /year in urbanized catchments vs. $1170 \mathrm{~mm}$ /year falling in rural catchments), and the ratios of the precipitation values of each pair (urbanized to rural) ranged between 0.75 and 1.46 (median ratio: 1.02). The mean potential evapotranspiration differences were similar (1060 mm/year and $1040 \mathrm{~mm}$ /year for urbanized and rural catchments, respectively), with ratios of each pair ranging between 0.94 and 1.2 (median ratio: 1.02). The TI $A$ values in urbanized catchments ranged between $10 \%$ and $59 \%$ with a median value of $24.6 \%$, which is an indication that different urbanization stages 
could be encountered in this sample. The $T$ I A range of their rural neighbors was $0 \%-5 \%$ with a median value of $1.2 \%$.

\subsection{Hydrological signatures used to assess the differences between rural and urbanized catchments}

Several hydrological signatures were analyzed to assess the differences in hydrological behavior between rural and urbanized catchments. We focused on four complementary and commonly used hydrological signatures: (1) the catchment yield, i.e., how much of precipitation was converted to streamflow; (2) the importance of the low-frequency component, i.e., the baseflow, with regard to the total flow; (3) the characteristic response time, which informs about how rapid the catchment response was; and (4) the capacity of the catchment in damping precipitation flashiness (Baker et al., 2004). For each one of these four aspects, the hydrological indicator was computed as follows:

1. The $Q_{\text {mean }} / P_{\text {mean }}(-)$ ratio, where $Q_{\text {mean }}$ is the mean annual streamflow depth and $P_{\text {mean }}$ the mean annual precipitation depth.

2. The baseflow index BFI (-), which is the ratio of total baseflow volume to total streamflow volume. The baseflow signal was extracted from the total streamflow time series using a combination of the constant- $k$ method (Blume, Zehe, and Bronstert, 2007) and recursive digital filtering (Mei and Anagnostou, 2015; Eckhardt, 2005; Collischonn and Fan, 2013).

3. The characteristic response time $D T(\mathrm{~h})$, which was taken as the applied shift on the streamflow time series that maximizes its correlation with the precipitation time series.

4. The $F Q / F P(-)$ ratio, where $F Q$ (or $F P$ ) is the flashiness of observed streamflow (or precipitation). The flashiness $F X$ of a signal $X$ was computed as (Holko et al., 2011; Baker et al., 2004):

$$
F X=\frac{\sum_{h}\left|X_{h}-X_{h-1}\right|}{\sum_{h} X_{h}}
$$

where $X_{h}$ is the value of $X$ at hour $h$.

\subsection{Assessment of the differences between urbanized and rural catchments from a rural modeling standpoint}

Urbanized catchments are generally characterized by quick runoff generation and propagation due to surface sealing and artificial drainage systems, which imposes a choice of fine modeling time steps (hourly to sub-hourly) to accurately represent the rainfall-runoff relationship in urbanized areas (Dotto et al., 2011; Rodriguez, Andrieu, and Morena, 2008; Salvadore, Bronders, and Batelaan, 2015). We have chosen the hourly time step as a compromise between hydroclimatic data availability and the need for a high temporal resolution to capture as much as possible the dynamics of the hydrological processes in urbanized catchments. Moreover, the characteristic response time $D T$ was at least one hour for the majority of catchments used here (347 out of 350 catchments).

In this study, we used two hourly conceptual rainfall-runoff models, GR4H (Ficchì, Perrin, and Andréassian, 2019) and IHACRES (Jakeman, Littlewood, and Whitehead, 1990). These two models were not 
developed specifically for urbanized catchments, but they showed their flexibility on a large range of hydrological behaviors. Thus, they were considered to be good candidates to investigate their flexibility over urbanized catchments. The choice of these models was also motivated by their parsimony (GR4H and IHACRES have four and six parameters, respectively, and require only hourly precipitation $P$ and potential evapotranspiration $E$ for forcing; see Figure 3). In this way, the model parameter values could be more easily interpreted with respect to catchment behavioral properties. We considered the impact of urbanization on: (i) model performance, (ii) calibrated model parameter values, and (iii) simulated internal fluxes.

The first level of comparison concerned the ability of the model to reproduce the observed streamflow. To this end, a split-sample test was used (Klemeš, 1986). The catchment period of recording was divided into two subperiods P1 and P2. For each subperiod, each model was calibrated with respect to the Kling-Gupta efficiency ( $K G E$ ) coefficient (Gupta et al., 2009), which measures the differences between two signals using their correlation, the ratio of their means, and the ratio of their standard deviations. The square root transformation was applied to the simulated and observed streamflows in order to guarantee the most uniform weighting possible over the different components of the streamflow (i.e., high, medium, and low flows; see Oudin et al., 2006; Santos, Thirel, and Perrin, 2018). For calibration, an algorithm consisting of a broad inspection of the model parameter hyperspace, followed by a gradient descent algorithm, was used (Edijatno et al., 1999). The calibrated parameters were then tested on the alternative period (i.e., P2 if calibrated on P1 and P1 if calibrated on P2). Performances were analyzed over the whole test period. In more detail, the models were also compared during the summer (June-August) and the winter (December-February) within the test period, in order to see whether the dry/humid contrast attenuated or accentuated the differences between the rural and the urbanized catchments.

The second level concerned differences in the calibrated parameters. The distributions of model parameters were determined for each catchment set (rural and urbanized) and the differences interpreted in terms of model functioning. Figure 3 illustrates model structures, main parameters, as well as internal variables. Table 1 provides a brief description of the role of each model parameter.

The third level involved the comparison of internal fluxes simulated by the models to investigate whether the two models handled the urbanized catchment behavioral properties in a similar way. Fluxes were compared over the calibration period using the coefficient of determination $R^{2}$ and the Bias (i.e., ratio of means). The main structural differences between GR4H and IHACRES can be summarized as follows: (1) production is represented in GR4H using a soil moisture accounting reservoir, where percolation is quantified (Perc in Figure 3), while it is characterized in IHACRES based on the catchment moisture deficit parametrized as an exponential decay function. In GR4H, the percolation flux Perc sustains the net precipitation $P R_{G R}$ in the absence of events, which fortifies the low-frequency behavior of $P R_{G R}$. (2) The quick flow/slow flow bifurcation is better identified in IHACRES than in GR4H, first through an optimized partitioning parameter ( $X_{2, I H A C}$ vs. the fixed 0.1-0.9 partitioning in GR4H), and second by removing any possible exchange between both branches in IHACRES. In GR4H, a groundwater exchange function interacts with both branches, which eventually influences the simulated water budget. Table 2 summarizes the comparison between GR4H and IHACRES fluxes and states (see Figure 3 for the location of each flux within the model structure). 
(a) GR4H

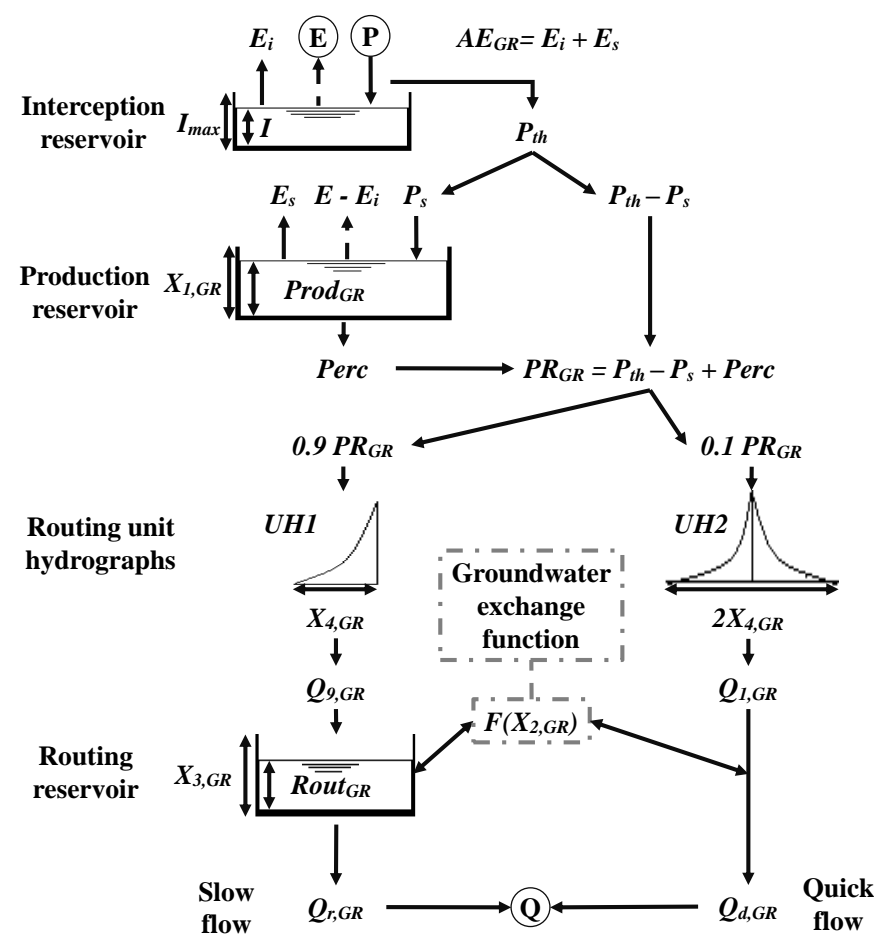

(b) IHACRES

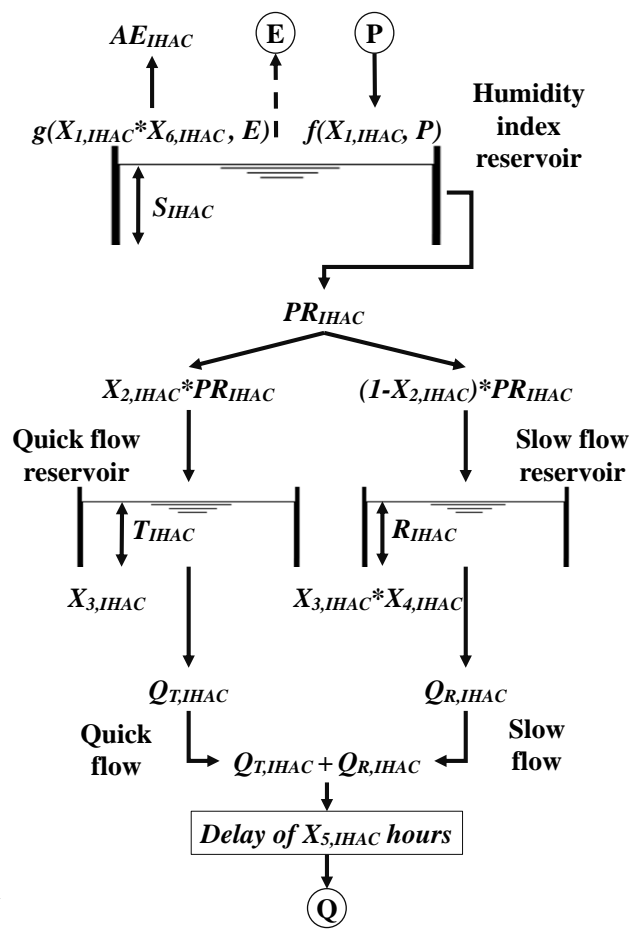

\section{Inputs (mm)}

P: Precipitation

E: Potential evapotranspiration

\section{GR4H parameters}

$\mathbf{I}_{\mathbf{m a x}}, \mathbf{X}_{\mathbf{1}, \mathbf{G R}}, \mathbf{X}_{\mathbf{3}, \mathbf{G R}}$ : Reservoir capacities (mm)

$\mathbf{X}_{\mathbf{2}, \mathbf{G R}}$ : Potential exchange parameter $(\mathrm{mm} / \mathrm{h})$

$\mathbf{X}_{\mathbf{4 , G R}}$ : Base time of unit hydrographs (h)

GR4H states (mm)

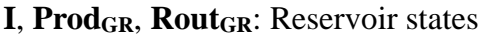

GR4H internal fluxes and outputs ( $\mathrm{mm}$ )

$\mathbf{E}_{\mathbf{i}}, \mathbf{E}_{\mathbf{s}}, \mathbf{A E}_{\mathbf{G R}}$ : Actual evapotranspiration

$\mathbf{P}_{\text {th: }}$ : Throughfall

$\mathbf{P}_{\text {s: }}$ Infiltration

Perc: Percolation

PR $_{\text {GR: Net precipitation }}$

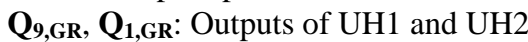

F: Potential exchange with groundwater

Qr,GR: Slow flow

$\mathbf{Q}_{\mathrm{d}, \mathrm{GR}}$ : Quick flow

Q: Total flow

\section{IHACRES parameters}

$\mathbf{X}_{1, \text { IHAC: }}$ Forcing parameter (P) (mm)

$\mathbf{X}_{1, \text { IHAC }} * \mathbf{X}_{\mathbf{6}, \text { IHAC }}$ : Forcing parameter (E) (mm)

$\mathbf{X}_{2, \text { IHAC: }}$ Quick flow-slow flow partitioning (-)

$\mathbf{X}_{3, \text { IHAC: }}$ Quick flow linear reservoir parameter (-)

$\mathbf{X}_{\mathbf{3}, \mathrm{IHAC}} * \mathbf{X}_{\mathbf{4}, \mathrm{IHAC}}$ : Slow flow linear reservoir parameter (-)

$\mathbf{X}_{5, \text { IHAC: Delay parameter (h) }}$

IHACRES states

SIHAC: Humidity index (-)

T IHAC, $_{\text {IHAC: }}$ Reservoir states (mm)

IHACRES internal fluxes and outputs ( $\mathrm{mm}$ )

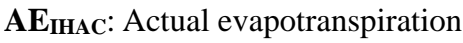

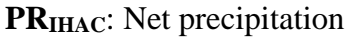

$Q_{\text {R,IHAC: Slow flow }}$

QT,IHAC: Quick flow

Q: Total flow

Figure 3. (a) GR4H and (b) IHACRES model structures. A detailed description of the GR4H model equations can be found in Ficchì, Perrin, and Andréassian (2019). The IHACRES model structure used here was derived from a rewriting of the original equations in a reservoir style by Perrin (2000), which was tested later at the hourly time step by Mathevet (2005). The numerically calibrated model parameters for GR4H and IHACRES are noted as $\left\{X_{i, G R}\right\}_{1 \leq i \leq 4}$ and $\left\{X_{j, I H A C}\right\}_{1 \leq j \leq 6}$, respectively. 
Table 1. Description of GR4H and IHACRES model parameters and their corresponding roles.

\begin{tabular}{|c|c|c|}
\hline Model & $\begin{array}{l}\text { Parameter notation and } \\
\text { unit }\end{array}$ & Role \\
\hline \multirow{4}{*}{ GR4H } & $X_{1, G R}(\mathrm{~mm})$ & $\begin{array}{l}\text { The maximum capacity of the soil moisture } \\
\text { accounting reservoir. This can be interpreted } \\
\text { as the capacity of the catchment soil to store } \\
\text { water. Higher values are associated with low net } \\
\text { precipitation } P R_{G R} \text {. }\end{array}$ \\
\hline & $X_{2, G R}(\mathrm{~mm} / \mathrm{h})$ & $\begin{array}{l}\text { The potential gain from/loss to groundwater. } \\
\text { Higher absolute values indicate higher potential } \\
\text { amounts of exchanged water. }\end{array}$ \\
\hline & $X_{3, G R}(\mathrm{~mm})$ & $\begin{array}{l}\text { The maximum capacity of the routing reservoir. } \\
\text { This controls the slow flow component } Q_{r, G R} \text {. } \\
\text { Higher values are associated with the long- } \\
\text { term memory of the catchment, i.e., important } \\
\text { volumes of slow flow } Q_{r, G R} \text {. }\end{array}$ \\
\hline & $X_{4, G R}(\mathrm{~h})$ & $\begin{array}{l}\text { The base time of the unit hydrographs, which is } \\
\text { correlated with the characteristic response time } \\
\text { of the catchment. }\end{array}$ \\
\hline \multirow{6}{*}{ IHACRES } & $X_{1, I H A C}(\mathrm{~mm})$ & $\begin{array}{l}\text { This controls the increase in the humidity index } \\
S_{I H A C} \text { due to precipitation. Higher values lead } \\
\text { to smaller increases of } S_{I H A C} \text { at the event scale, } \\
\text { hence less net precipitation } P R_{I H A C} \text {. }\end{array}$ \\
\hline & $X_{1, I H A C} \cdot X_{6, I H A C}(\mathrm{~mm})$ & $\begin{array}{l}\text { This controls the decrease in } S_{I H A C} \text { due to } \\
\text { evapotranspiration. Higher values indicate a } \\
\text { slower decrease of } S_{I H A C} \text {. }\end{array}$ \\
\hline & $X_{2, I H A C}(-)$ & $\begin{array}{l}\text { This influences the slow flow/quick flow routing } \\
\text { partitioning. Higher values indicate that the net } \\
\text { precipitation } P R_{I H A C} \text { passes mainly through the } \\
\text { fast flow branch. }\end{array}$ \\
\hline & $X_{3, I H A C}(-)$ & $\begin{array}{l}\text { This controls the amount of the quick discharge } \\
Q_{T, I H A C} \text {, for which higher values indicate lower } \\
\text { amounts of } Q_{T, I H A C} \text {. }\end{array}$ \\
\hline & $X_{3, I H A C} \cdot X_{4, I H A C}(-)$ & $\begin{array}{l}\text { This controls the slow flow } Q_{R, I H A C} \text {. Higher } \\
\text { values of } X_{3, I H A C} \cdot X_{4, I H A C} \text { are associated with } \\
\text { low quantities of } Q_{R, I H A C} \text {. }\end{array}$ \\
\hline & $X_{5, I H A C}(\mathrm{~h})$ & $\begin{array}{l}\text { The delay to be applied on }\left(Q_{T, I H A C}+Q_{R, I H A C}\right) \text {, } \\
\text { the sum of the quick and slow flows. This } \\
\text { characterizes the rapidity of the catchment } \\
\text { response. }\end{array}$ \\
\hline
\end{tabular}


Table 2. Comparison of GR4H and IHACRES internal fluxes and states.

\begin{tabular}{l|l|l|l}
\hline \multicolumn{1}{c|}{ Internal fluxes/states } & \multicolumn{1}{|c|}{$\begin{array}{c}\text { Corresponding GR4H } \\
\text { flux/state }\end{array}$} & $\begin{array}{l}\text { Corresponding IHACRES } \\
\text { flux/state }\end{array}$ & \multicolumn{1}{c}{$\begin{array}{c}\text { Comparison } \\
\text { metrics }\end{array}$} \\
\hline $\begin{array}{l}\text { Catchment humidity } \\
\text { state }\end{array}$ & $\begin{array}{l}\text { Production reservoir state } \\
\operatorname{Prod}_{G R}\end{array}$ & Humidity index $S_{I H A C}$ & $R^{2}$ \\
\hline Net precipitation & $P R_{G R}$ & $P R_{I H A C}$ & $R^{2}$, Bias \\
\hline $\begin{array}{l}\text { Actual evapotranspira- } \\
\text { tion }\end{array}$ & Sum of $E_{i}$ and $E_{S}\left(A E_{G R}\right)$ & $\begin{array}{l}\text { Sum of decreases in } S_{I H A C} \\
\text { multiplied by } X_{1, I H A C} \\
\left(A E_{I H A C}\right)\end{array}$ & Bias \\
\hline Total losses & $\begin{array}{l}\text { Sum of } A E_{G R} \text { and the ex- } \\
\text { ports to the groundwater } \\
\left(L O S S_{G R}\right)\end{array}$ & $A E_{I H A C}$ & Bias \\
\hline Slow flow routing & $\begin{array}{l}\text { Routing reservoir state } \\
\text { Rout }\end{array}$ & $\begin{array}{l}\text { Slow flow reservoir state } \\
R_{I H A C}\end{array}$ & $R^{2}$ \\
\hline Slow flow & Slow branch output $Q_{r, G R}$ & $\begin{array}{l}\text { Slow flow reservoir output } \\
Q_{R, I H A C}\end{array}$ & $R^{2}$, Bias \\
\hline Quick flow & Quick branch output $Q_{d, G R}$ & $\begin{array}{l}\text { Quick flow reservoir output } \\
Q_{T, I H A C}\end{array}$ & $R^{2}$, Bias \\
\hline Total flow & Simulated flow $Q\left(Q_{s i m, G R}\right)$ & $\begin{array}{l}\text { Simulated flow } \\
\left(Q_{\text {sim,IHAC }}\right)\end{array}$ & $R^{2}$, Bias \\
\hline
\end{tabular}

\section{Results}

\subsection{Are urbanized catchments hydrologically different from their rural neighbors?}

In general, all the hydrological signatures of the urbanized catchments deviated from those of their rural neighbors, as illustrated in Figure 4. At low levels of $T$ I A, urbanized catchments exhibited values similar to their rural neighbors, and the greater the $T$ IA, the more the deviation between the two samples increased. These results suggest that urbanization impacted all facets of hydrological behavior. However, in terms of range (or distribution), the hydrological signatures of urbanized catchments were not so different from those of rural catchments. This means that the large diversity encountered in rural catchments encompassed the specificities of the urbanized ones. This was true for all the considered hydrological signatures, except for the flashiness ratio $F Q / F P$, which showed very high values in urbanized catchments compared with rural catchments.

For a given volume of precipitation, results on $Q_{\text {mean }} / P_{\text {mean }}$ (Figure $4 \mathrm{a}$ ) indicate that it is more likely to have a higher volume of streamflow in an urbanized catchment than in a rural one: median $Q_{\text {mean }} / P_{\text {mean }}$ ratio reached 0.39 in urbanized cases, while it was around 0.27 in rural catchments. Conversely, median baseflow index (Figure $4 \mathrm{~b}$ ) was higher in rural contexts ( 0.62 vs. 0.42 in urbanized catchments), indicating that, for the majority of pairs, low flow decreased in urbanized catchments. The characteristic response times $D T$ (Figure 4c) were much shorter in urbanized catchments compared with rural catchments (a median $D T$ of $3 \mathrm{~h}$ for urbanized catchments vs. $14 \mathrm{~h}$ for their rural neighbors), suggesting faster responses for the urbanized cases. Also, FQ/FP ratios (Figure $4 \mathrm{~d}$ ) were much higher in high-imperviousness catchments (a median of 0.13 vs. 0.03 in rural catchments), implying that the temporal irregularities of precipitation were more damped in rural catchments than in urbanized ones. 

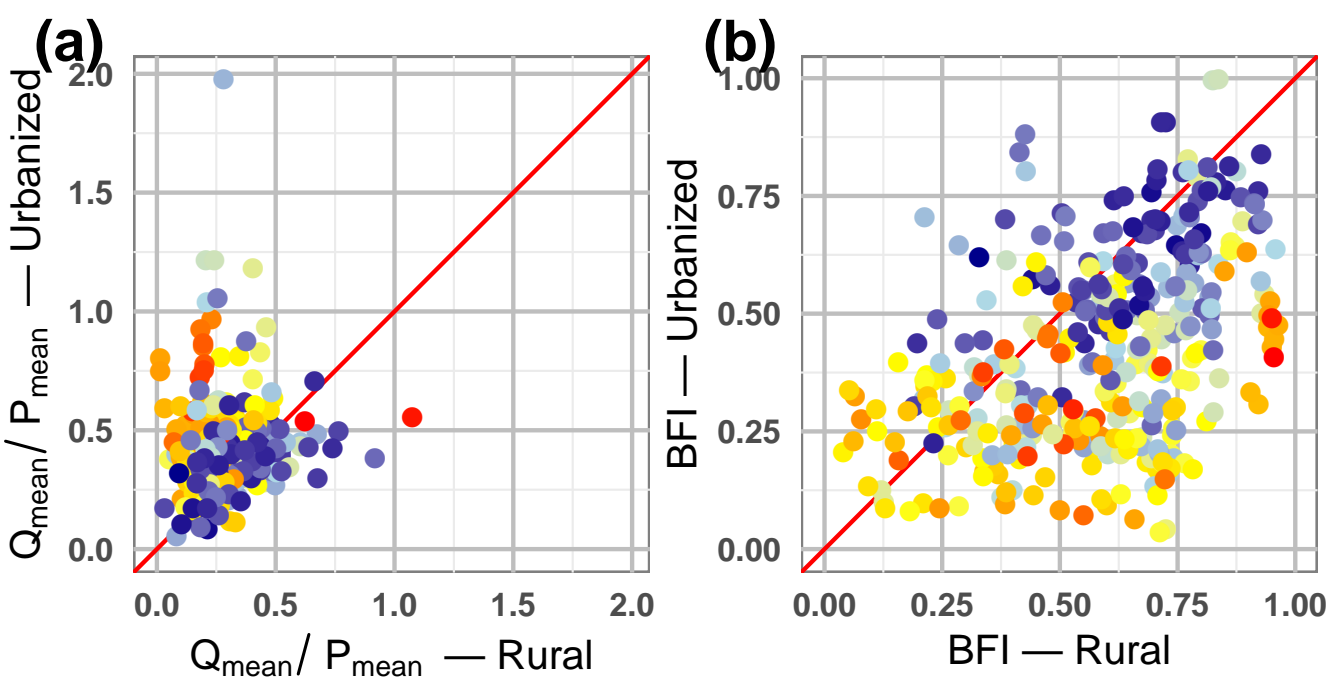

TIA (\%)
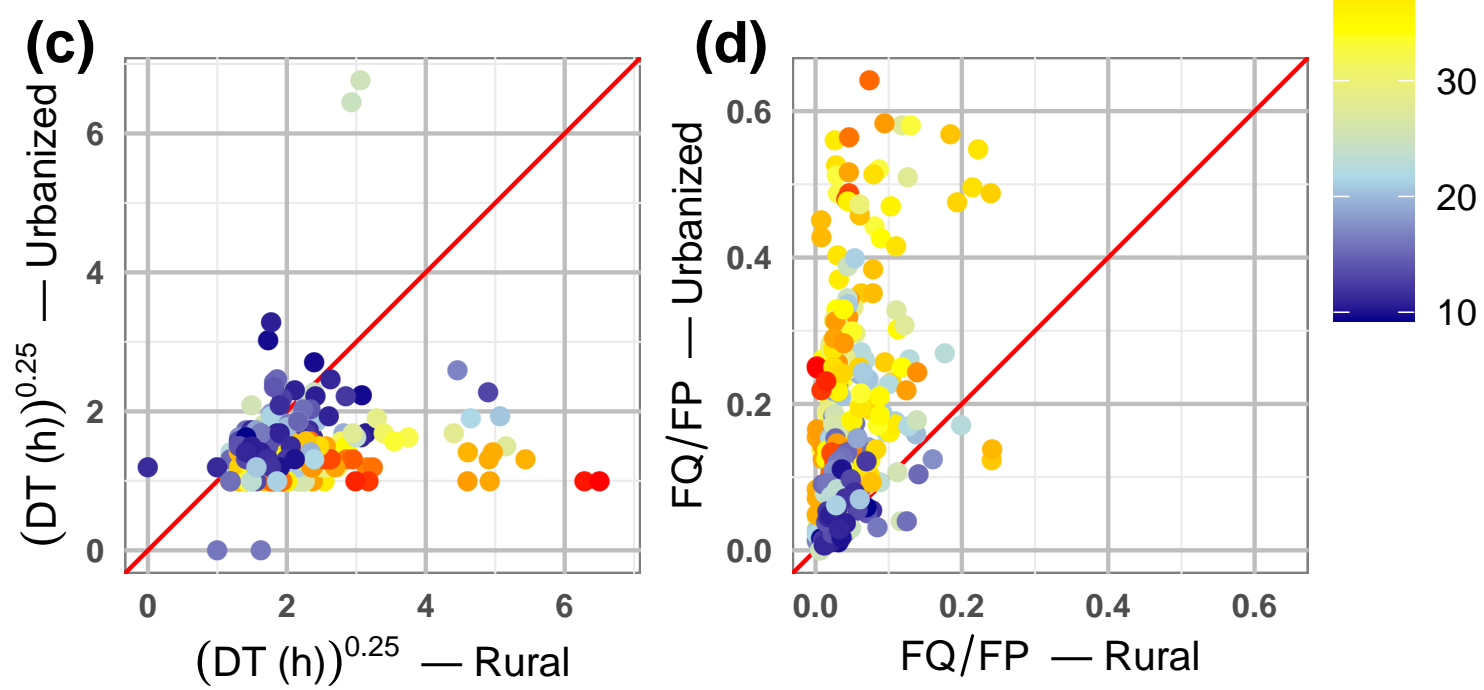

Figure 4. Values of the hydrological signatures for urbanized catchments (on $y$-axes) vs. their rural neighbors (on $x$-axes): (a) the ratio of mean annual streamflow to mean annual precipitation $\left(Q_{\text {mean }} / P_{\text {mean }}\right)$, (b) the baseflow index $(B F I)$, (c) the characteristic response time $(D T)$, and (d) the ratio of streamflow flashiness to precipitation flashiness $(F Q / F P)$. Colors indicate the mean total impervious area $(T I A)$ of the urbanized catchment, which ranged between $10 \%$ and $59 \%$. The $T I A$ range of their rural neighbors was $0 \%-5 \%$. Some catchments show abnormal values of $Q_{\text {mean }} / P_{\text {mean }}$ ratio (i.e., higher than 1). These values were exhibited by catchments whose outlets were generally within or close to an urban settlement (these included the USGS station 08116400 on the Dry Creek near Rosenberg, Texas, and the USGS station 02310525 on the Weeki Wachee River near Brooksville, Florida). 


\subsection{Are there differences between urbanized and rural catchments observable from a rural modeling standpoint?}

In terms of model performances, GR4H revealed no clear distinction between urbanized and rural catchments, whereas IHACRES simulated better urbanized catchments, especially during summer (Figure 5). The parameter distributions of both models were impacted by urbanization (Figures 6 and 7), as well as the agreement of GR4H and IHACRES in terms of internal fluxes (Figure 8).

Our first level of investigation is model performances, as one would expect that rural models would not be suitable for urbanized catchments given the differences in landscape and hydrological behavior. Concerning calibration (Figure 5), both conceptual models showed similar performances over the rural and urbanized catchment sets, meaning that these models were flexible enough to reproduce the rainfall-runoff relationship for the urbanized catchments. IHACRES showed even greater ability in reproducing observed flows in urbanized catchments than in rural ones. Test performances showed a drop in median performances of about 0.07-0.08 of KGE in a similar manner for both models over both catchment samples. When the evaluation concerned only the summer or the winter periods, performances decreased, especially for the summer-based evaluation. However, it is during the summer when IHACRES test performances were significantly better in the urbanized catchments compared with their rural neighbors, as the corresponding difference in median $K G E$ reached 0.09 .

Since GR4H and IHACRES performances were satisfactory for both urbanized and rural catchments, their parameters could be now compared so as to see which ones were impacted by urbanization. We can notice that non-impacted performances of GR4H (Figure 5) were countered by different parameter distributions for rural and urbanized catchments, as shown in Figure 6. In urbanized catchments, $X_{1, G R}$ showed slightly higher values than in rural ones. On the other hand, $X_{2, G R}$ was more centered on zero in the urbanized set, while it became negative in the majority of rural catchments, meaning that rural catchments exported more water to groundwater compared with urbanized catchments. These two variations for $X_{1, G R}$ and $X_{2, G R}$ yield more runoff for the urbanized catchments, by reducing the losses through evapotranspiration and deep infiltration. The differences were more pronounced concerning $X_{3, G R}$ and $X_{4, G R}$, for which lower values were encountered in the urbanized catchments compared with rural ones. This suggests a short-term memory behavior and more pronounced low flows over urbanized catchments, accompanied by a faster response compared with rural contexts. 

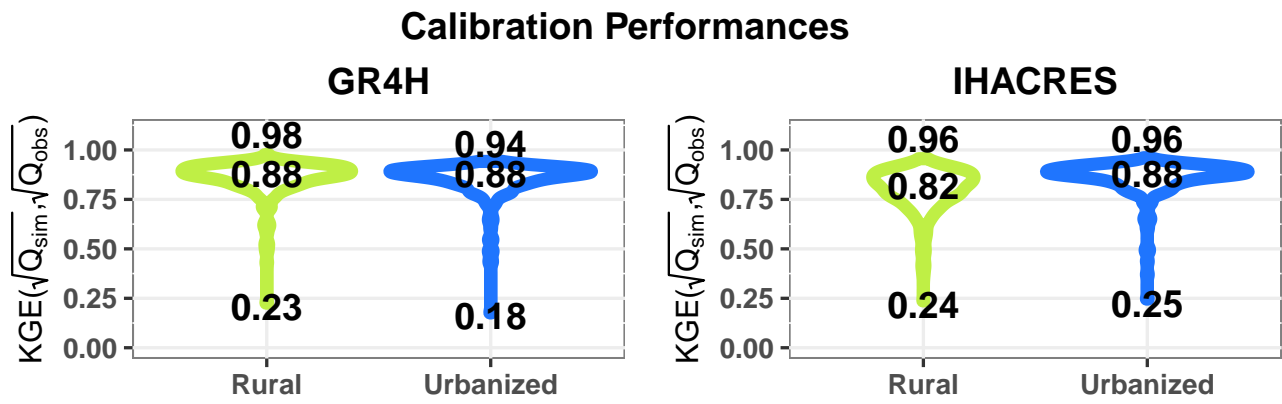

Test Performances

GR4H

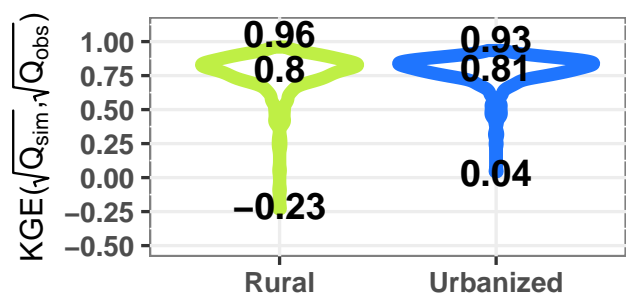

IHACRES

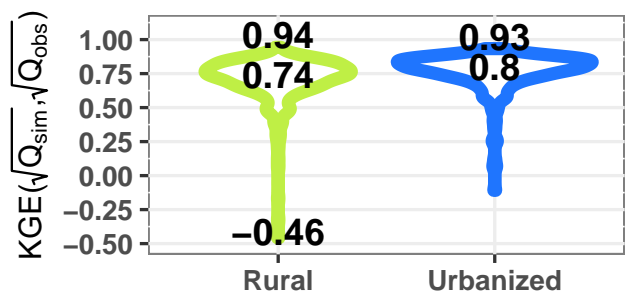

Test Performances - Winter

GR4H

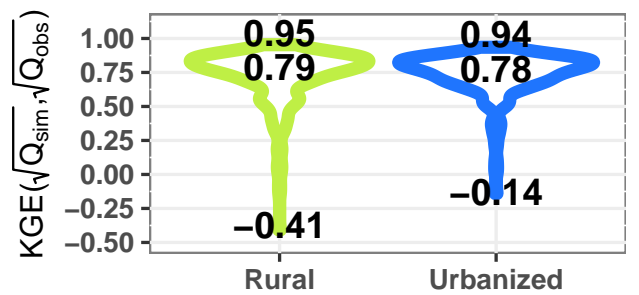

IHACRES

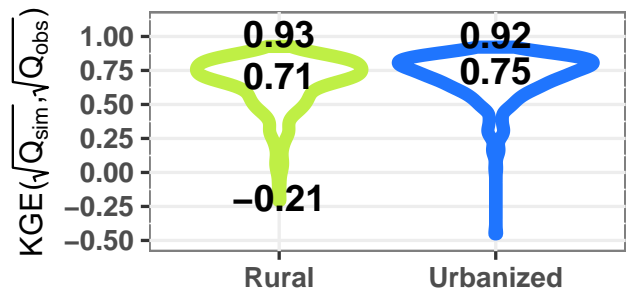

Test Performances - Summer

GR4H

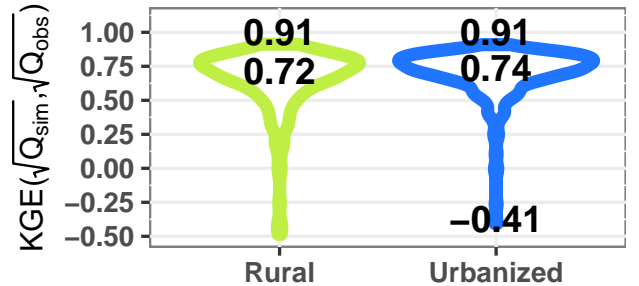

IHACRES

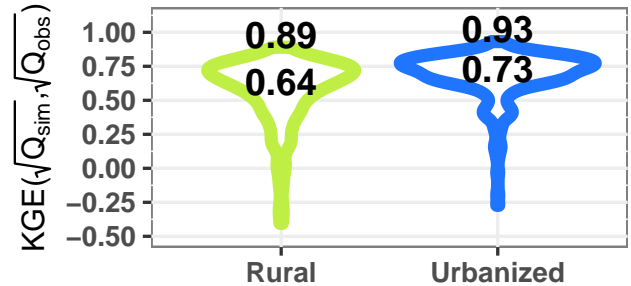

Figure 5. Distributions of GR4H (left column) and IHACRES (right column) performances in calibration (first row) and test over the whole test period (second row), with a focus on the winter (third row) and the summer periods (fourth row). Performances are shown for the urbanized catchments (Urbanized, in blue) and their rural neighbors ( $R$ ural, in green). The assessment is shown in terms of the Kling-Gupta Efficiency $(K G E)$ score applied on square root values of simulated $\left(Q_{s i m}\right)$ and observed $\left(Q_{o b s}\right)$ streamflow time series. Values indicate the minimum, the median, and the maximum. It should be remembered that the ideal value of $K G E$ is 1 . In many cases, the minimum $K G E$ values for rural and urbanized catchments were lower than -0.5 (Test performances over whole period: IHACRES-Urbanized: -0.76 ; Test performances, focus on winter: IHACRES-Urbanized: -1.24 ; Test performances, focus on summer: GR4HRural: -11.04, IHACRES-Rural: -22.00, IHACRES-Urbanized: -1.06). 

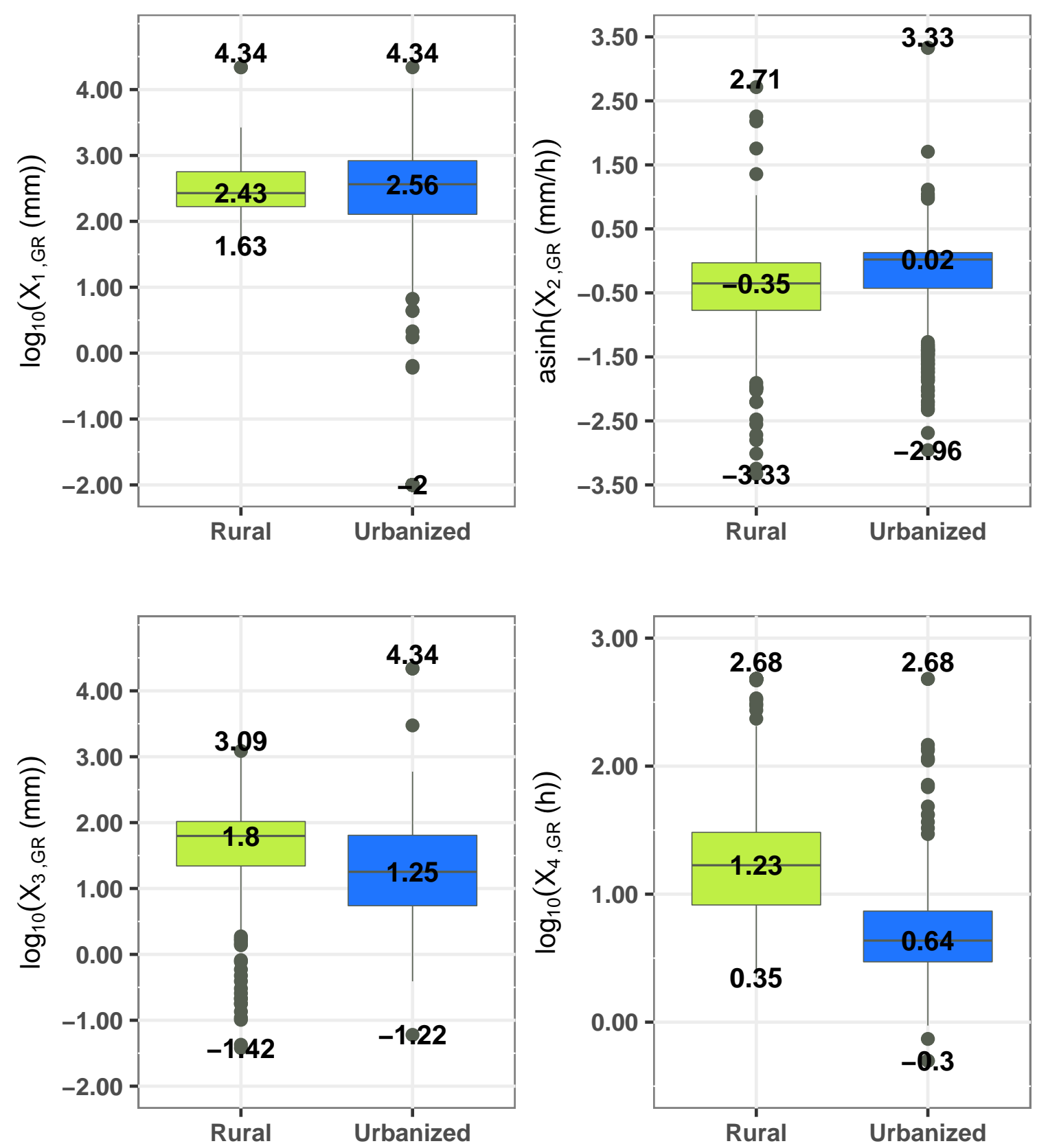

Figure 6. Distributions of GR4H parameters over the urbanized catchments (in blue) and their rural neighbors (in green). According to Student's $t$-test (Section 6), all differences between rural and urbanized samples were statistically significant ( $p$-value $<0.001$ ), except for $X_{1, G R}$. MannWhitney-Wilcoxon test (Section 6) indicated that all parameter distributions were statistically different ( $p$-value $<0.001$ ). Transformations were applied to better normalize the distributions. Values indicate the minimum, the median, and the maximum. Boxes are delimitated by the first and third quartiles. 
Considering IHACRES parameters, the differences can be identified for each parameter, as illustrated in Figure 7. The parameter $X_{1, I H A C}$ was significantly lower in urbanized catchments than in rural ones, indicating that the humidity index $S_{I H A C}$ increased more quickly at the event scale in urbanized catchments, thus converting a higher portion of precipitation into runoff compared with rural catchments. However, $X_{1, I H A C} \cdot X_{6, I H A C}$ indicates that $S_{I H A C}$ tended to decrease more quickly in urbanized catchments, especially during dry periods, but the fact that $X_{1, I H A C}$ was lower in this set indicates that the urbanized catchments responded more sensitively to summer events (i.e., dry-period events, due to quick increase in $S_{I H A C}$ ) than their rural neighbors did. Therefore, the variance of $S_{I H A C}$ was higher in urbanized catchments. The $X_{2, I H A C}$ parameter was higher in urbanized catchments, which indicates that the excess water during an event passed mostly through the quick flow branch. Conversely, the $X_{3, I H A C}$ values were lower in the urbanized set, whereas the $X_{3, I H A C} \cdot X_{4, I H A C}$ product values were higher. This indicates that the quick flow volumes were higher in urbanized catchments, while slow flow volumes were higher in rural catchments. The low values of $X_{5, I H A C}$ encountered in urbanized catchments suggest that they reacted faster than their rural neighbors. 

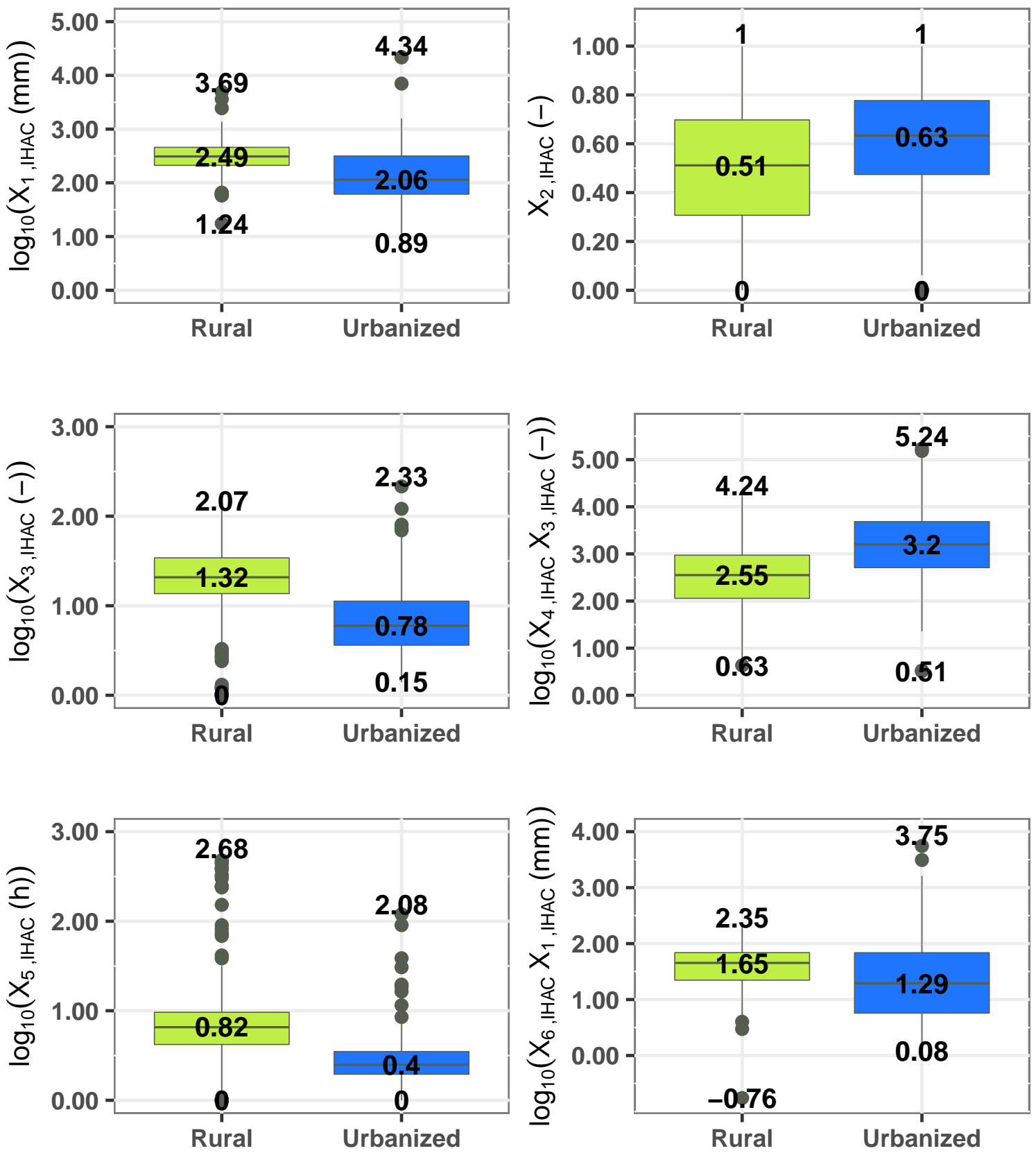

Figure 7. Distributions of IHACRES parameters in the urbanized catchments (in blue) and their rural neighbors (in green). According to Student's $t$-test (Section 6), all differences between rural and urbanized samples were statistically significant ( $p$-value $<0.001$ ). Mann-Whitney-Wilcoxon test (Section 6 ) indicated that all parameter distributions were statistically different ( $p$-value $<$ 0.001). Transformations were applied to better normalize the distributions. Values indicate the minimum, the median, and the maximum. Boxes are delimitated by the first and third quartiles.

Finally, it is noteworthy to examine the internal fluxes and outputs of both models, first to see whether GR4H and IHACRES simulated similarly the rural catchments, and if so, whether this agreement was altered by urbanization. In this respect, GR4H and IHACRES internal fluxes were more similar in rural catchments than in urbanized ones, indicating impacted internal model fluxes and states by 
urbanization, as shown in Figure 8 by the median values of $R^{2}$ and the Bias on the internal model fluxes and states (listed in Table 2).

In terms of $R^{2}$, the internal states of the models (i.e., $\operatorname{Prod}_{G R}$ vs. $S_{I H A C}$ and $\operatorname{Rout}_{G R}$ vs. $R_{I H A C}$ ) showed higher correlations when simulating the rural catchments $\left(R^{2}\left(\operatorname{Prod}_{G R}, S_{I H A C}\right)=0.69\right.$ and $R^{2}\left(\right.$ Rout $\left._{G R}, R_{I H A C}\right)=0.53$, median values) than the urbanized catchments. Correlations in reproducing the net precipitation $P R$ were comparatively high, with median $R^{2}$ values of approximately 0.9 in rural catchments compared with 0.76 for urbanized catchments. Both models disagreed significantly in simulating slow flow, whereas they agreed in terms of the quick flow, with a slightly higher median correlation in urbanized catchments than in rural ones. Finally, although not as strongly correlated as when simulating net precipitation, the models simulated total flow in a relatively similar manner, with slightly higher correlations in rural catchments than in urbanized ones (rural median $R^{2}\left(Q_{s i m, G R}, Q_{\text {sim,IHAC }}\right)$ attaining 0.78 vs. $R^{2}\left(Q_{s i m, G R}, Q_{\text {sim, } I H A C}\right)$ median value of 0.73 for the urbanized catchments).

The Bias terms showed weaker agreement in reproducing the volumes of the analyzed fluxes. With the exception of the simulated streamflows, the values of $\operatorname{Bias}\left(P R_{G R}, P R_{I H A C}\right)$ were the closest to 1, with slightly higher amounts of $P R_{G R}$ produced in rural catchments compared with $P R_{I H A C}$ (i.e., $\left.\operatorname{Bias}\left(P R_{G R}, P R_{I H A C}\right)>1.0\right)$. The total losses estimated in GR4H were generally lower than the ones estimated in IHACRES. Slow flow volumes were significantly lower in IHACRES than in GR4H, while the inverse was the case for quick flow volumes. Ultimately, the total simulated flows were virtually the same, leading to a median Bbias very close to 1 .

\section{Discussion}

\subsection{Impact of urbanization on the hydrological behavior of catchments}

Our purpose of comparing the hydrological behavior of urbanized catchments with that of their rural neighbors was to check whether landscape differences (i.e., urbanized vs. non-urbanized) impacted hydrological characteristics. Overall, the obtained results corroborate the literature findings concerning the impact of urbanization, which has been a widely investigated question for decades (Leopold, 1968; Hollis, 1977; Oudin et al., 2018). In this regard, the original facets of our findings are twofold: (1) The examination of hydrological behavior by computing the signature metrics over continuous and relatively long hourly time series, in contrast with event- and season-based metrics (Miller and Hess, 2017; Zhou et al., 2017; Sillanpää and Koivusalo, 2015); (2) The use of a large sample of urbanized catchments in two different countries, which is a key strength in the context of abundant single-catchment experiments in urbanization studies (Salvadore, Bronders, and Batelaan, 2015).

In more detail, the high values $Q_{m e a n} / P_{\text {mean }}$ in urbanized catchments is in line with the large number of empirical studies showing that mean annual flows increase with urban development (DeWalle et al., 2000; Oudin et al., 2018), due to either increased imperviousness or the effluents of water treatment facilities (Diem, Hill, and Milligan, 2018; Zhou et al., 2017).

Conversely, the impact of urbanization on low flows is still difficult to assess. On one hand, the BFI could be higher in some urbanized catchments owing to water treatment facility releases during the dry period (Oudin et al., 2018), reduction in vegetation cover, or leakage in high-pressure potable water systems (Göbel et al., 2004; Lancia et al., 2019; Sanzana et al., 2019). On the other hand, BFI 


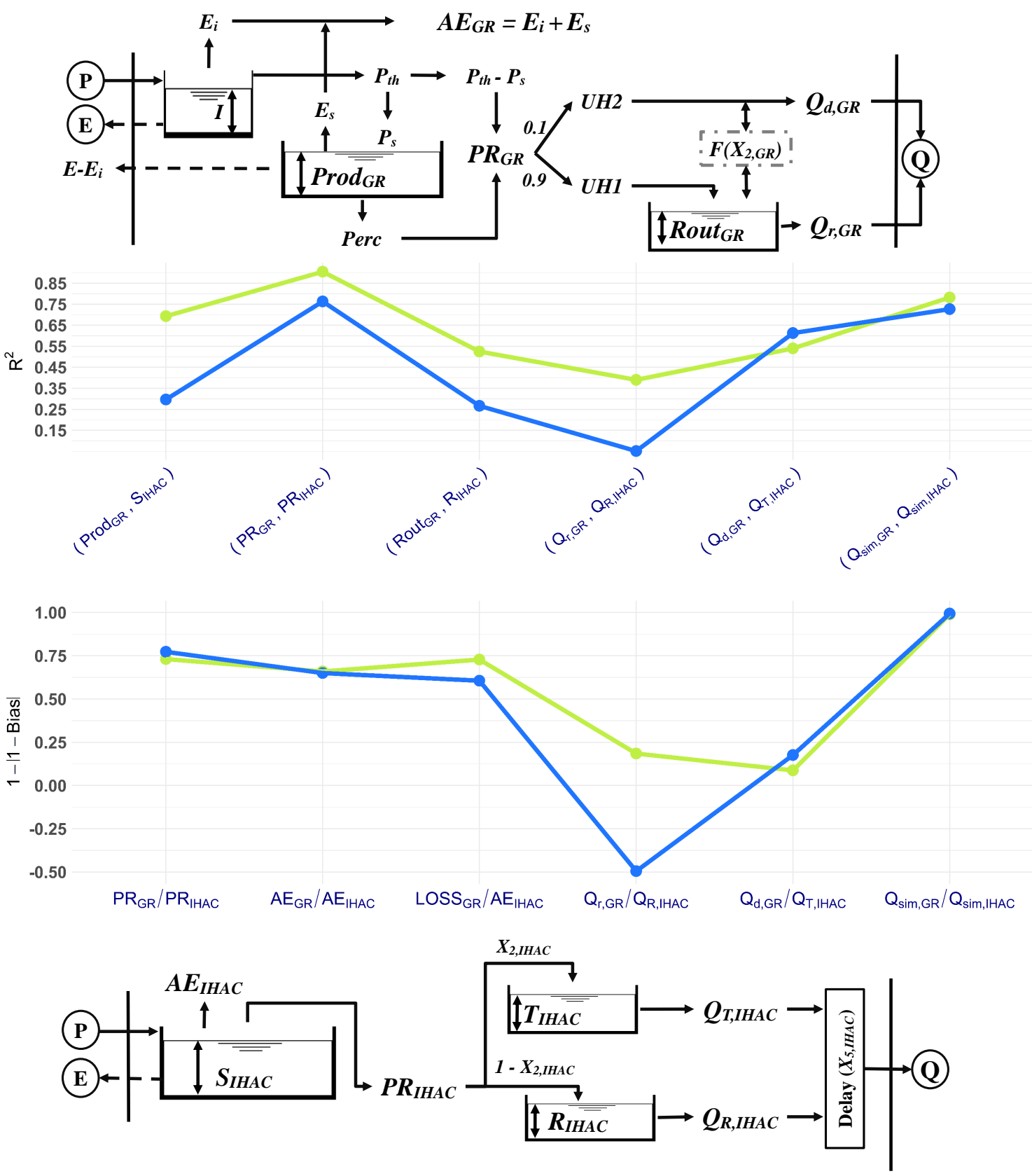

Figure 8. Comparison between different GR4H and IHACRES internal fluxes and states (listed in Table 2) in terms of median values of $R^{2}$ and the median distance of the bias (ratio of means) to 1 , in the rural (green lines) and urbanized catchments (blue lines). This comparison concerns the calibration period only. The meaning of acronyms of internal fluxes and states can be found in Figure 3. $\operatorname{LOSS}_{G R}$ is computed as the total losses via actual evapotranspiration and groundwater exchange. 
could be lower in some urbanized catchments in which groundwater pumping is intensive and the river-groundwater connection is cut by sealing the riverbanks (Braud et al., 2013; Brun and Band, 2000; Zektser and Everett, 2004). These two possible changes are observed in our catchment set, but for the majority, BFI decreased.

Flow velocities on sealed surfaces are higher than on natural ones (i.e., bare or vegetated soils), due to the reduction of surface roughness. This becomes pronounced with the higher amounts of runoff during an event, ultimately leading to an acceleration of the catchment response (Burns et al., 2005; Miller and Hess, 2017).

To conclude, we found that urbanization modified many facets of hydrological behavior, from water budget to high and low flow characteristics. However, of the signatures considered here, only FQ/FP showed significantly different ranges for the two catchment sets (rural and urbanized). This means that the impact of urbanization on hydrological behavior was not abrupt (Mejía et al., 2015), hence, the diversity of behaviors in rural catchments still encompasses the behaviors of the urbanized ones. Therefore, the large flashiness of the streamflow signal $(F Q / F P)$ is a very specific characteristic to distinguish urbanized from rural catchments.

\subsection{Differences between urbanized and rural catchments from a modeling standpoint}

\subsubsection{Detection of differences in hydrological behavior by model parameters}

The differences shown above in terms of GR4H and IHACRES parameters (Figures 6 and 7) are consistent with the obtained differences in the hydrological signatures (Figure 4). By shifting the production parameters (low mean $X_{1, G R}$, close-to-zero values of $X_{2, G R}$, and low $X_{1, I H A C}$ ), the models simulated higher $Q_{\text {mean }} / P_{\text {mean }}$ in the urbanized catchments, whereas lower values of $B F I$ (i.e., much smaller slow-flow component compared with quick flow) were confirmed by the routing parameters (lower values of $X_{3, G R}$, higher values of $X_{2, I H A C}$, lower values of $X_{3, I H A C}$, and higher values of $X_{3, I H A C} \cdot X_{4, I H A C}$ ). The rapid response and the high flashiness of the urbanized catchments, manifested by short $D T$ and high $F Q / F P$, were reflected by the timing parameters $\left(X_{4, G R}\right.$ and $\left.X_{5, I H A C}\right)$.

It may not be surprising that the parameters corroborate what we learn from the hydrological signatures, since the parameters were calibrated in such a way that the simulated outflows of the models match as closely as possible the observed streamflow time series in the urbanized catchments. This helped to infer the impact of urbanization from change in model parameters (McIntyre and Marshall, 2010; Pathiraja et al., 2018; Seibert and McDonnell, 2010). However, this is not usually straightforward, as the model parameters are not only land-use dependent, but also morphology-, geopedology-, and climatedependent (Merz, Parajka, and Blöschl, 2011), which might explain some of the parameter dispersion. Through a paired-catchment approach, some effects (e.g., related to climate and geopedology) are supposed to be limited, but not to the extent that we would be able to witness differences in parameter distributions based only on the imperviousness level. Besides, the use of a parsimonious model structure is a key factor in limiting the equifinality and the non-identifiability of the parameters (Beven, 2006; Ebel and Loague, 2006), without which interpretation might have been more difficult. 


\subsubsection{Flexibility of conceptual models with regard to urbanized catchments}

The performances of GR4H and IHACRES were not negatively impacted by urbanization (Figure 5). IHACRES and GR4H had similar performances over the urbanized catchment set, which were even better than their performances in rural catchments. This is an indication that conceptual models can be flexible enough to account for the specificities of urbanized catchments, which is likely due to the fact that the range of behaviors in rural catchments can encompass a wide range of those of urbanized catchments, as discussed above. Test performances registered a similar drop in performances regardless of urbanization, especially for the summer-based evaluation, a result that has been encountered in many model evaluation studies (Brigode, Oudin, and Perrin, 2013; Boer-Euser et al., 2017).

Although GR4H and IHACRES performances in urbanized catchments were more similar than in rural ones, they handled urbanized catchments more differently (Figure 8). Despite the fact that both models simulated runoff differently, their generated net precipitation fluxes $\left(P R_{G R}\right.$ and $\left.P R_{I H A C}\right)$ were highly correlated in rural catchments, but this agreement was less significant in urbanized catchments. It is reasonable to say that this good agreement is merely a response to the same precipitation forcing. However, the very significant drop in correlations encountered between $\operatorname{Prod}_{G R}$ and $S_{I H A C}$ states suggests that the models handle urbanization differently. Moreover, less agreement was found in the routing processes, perhaps because more freedom (i.e., free parameters) is left to IHACRES to better represent quick/slow flow partitioning than GR4H. This can be observed through the slow flow branch, for which the two models scored the lowest values of $R^{2}$. In addition, the Bias of $Q_{r, G R}$ and $Q_{R, I H A C}$ confirmed this disagreement in representing slow flows. The relatively high proportion of slow flow of GR4H was also perceived to be a structural characteristic (Boer-Euser et al., 2017). These differences in slow flow volumes were compensated for thanks to the quick flow branches reaching better concordance in simulated total flow volumes (Bias in $Q_{\text {sim }}$ around 1).

\section{Conclusion}

As a key finding of this study, conceptual models GR4H and IHACRES were flexible enough to reproduce the rainfall-runoff relationship of 175 US and French urbanized catchments. Also, the two models were able to handle the behavioral specificities of urbanized catchments, which we found to be deviated from the specificities of their rural neighbor catchments using four hydrological signature metrics.

Over a large sample of 175 urbanized catchments with $T I A>10 \%$, the hydrological characteristics, i.e., the $Q_{\text {mean }} / P_{\text {mean }}$ ratio (to analyze the catchment yield), the $B F I$ (to characterize the baseflow), the lag time $D T$ (to characterize the catchment response time), and the $F Q / F P$ ratio (to analyze the capacity of the catchment to damp precipitation flashiness), have confirmed the specificities of the hydrological behavior of urbanized catchments, which can be summarized as more runoff in a shorter span of time, with a reduction in the baseflow contribution. These specificities were demonstrated thanks to the paired-catchment style experiment, but it should be noted that, for the majority of characteristics $\left(Q_{\text {mean }} / P_{\text {mean }}, B F I\right.$ and $\left.D T\right)$, the urbanized catchment sample fell into the range of the rural catchments. Conversely, the flashiness ratio $(F Q / F P)$ in some urbanized catchments exceeded the range observed in rural catchments, making the flashiness of the response a marker of urbanized catchment behavior. 
Despite the absence of explicit urban-specific components within their structures, GR4H and IHACRES have shown satisfactory results in both rural and urbanized catchment sets. Specifically, GR4H handled both samples similarly, whereas IHACRES demonstrated greater ability to reproduce the rainfall-runoff relationship in urbanized catchments than in rural ones. The capacity of the models to reproduce the observed runoff in different states of urbanization ( $T$ I A between $10 \%$ and $59 \%$ ) has led to different parameter distributions for urbanized and rural catchments. These two points, i.e., good model performances and distinguishable parameter distributions, are promising for model-based evidence of the impact of urbanization on catchment behavior. This also corroborates the view that the urbanized catchment behavior is nothing more than a particular hydrological behavior, which is satisfactorily reproducible by a rural model and for which rural model parameters take different distributions when compared with a predominantly rural-landscaped catchment. However, we showed that GR4H and IHACRES handle urbanized catchments differently, owing to their structural differences and degrees of freedom, but both models were flexible enough to perform well in urbanized catchments.

This study provides the community with elements that could justify the application of rural models to urban-impacted catchments. For perspective studies, a sensitivity analysis with respect to different $T I A$ thresholds would clarify the urbanization level above which changes in hydrological behavior become significant. The fact that the models do not explicitly represent urban features makes their use for future scenarios impractical. Attempts at relating the parameters of a rural model to an urbanization measure have shown the weak sensitivity of the model parameters to changes in the urban measure (Saadi, Oudin, and Ribstein, 2019), meaning that an adaptation of their structure is needed in order to overcome these limitations.

\section{Supporting information}

We investigated the statistical significance of the differences between rural and urbanized samples using two tests: the Student's $t$-test which we applied on transformed values to analyze how significant the differences in terms of means were, and the Mann-Whitney-Wilcoxon test which we used to examine how significantly different the distributions were. We have considered the differences in hydrological signatures, model performances, and model parameter values. Results are summarized in Table 3. 


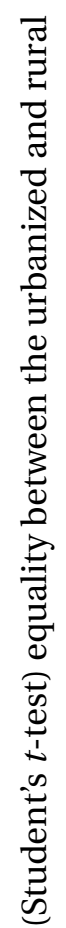

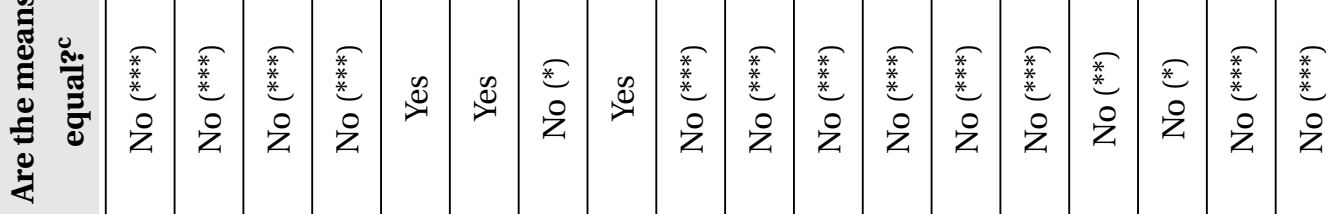

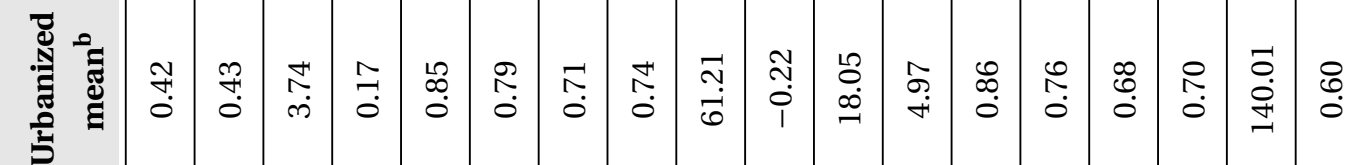

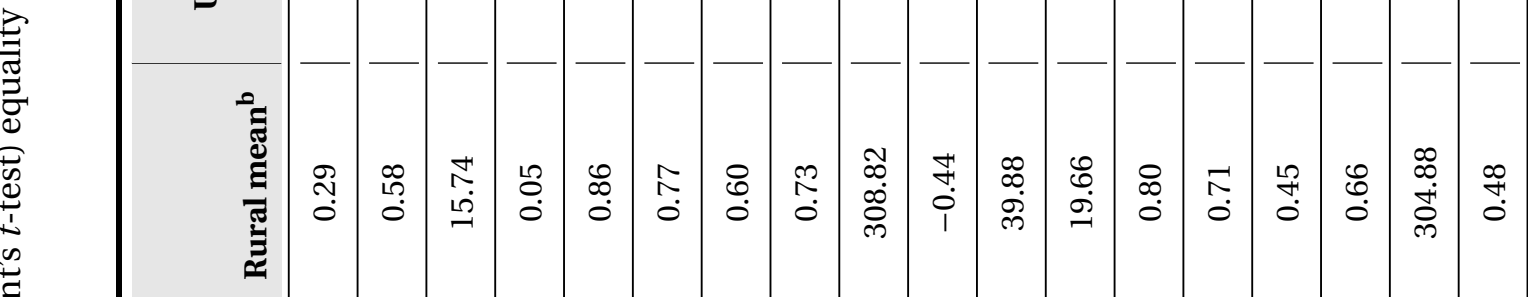

要

ฐึี

류 क्ष

ह

完

弯

(ํ)

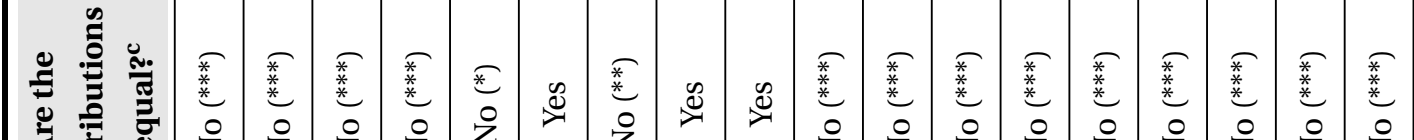
य 


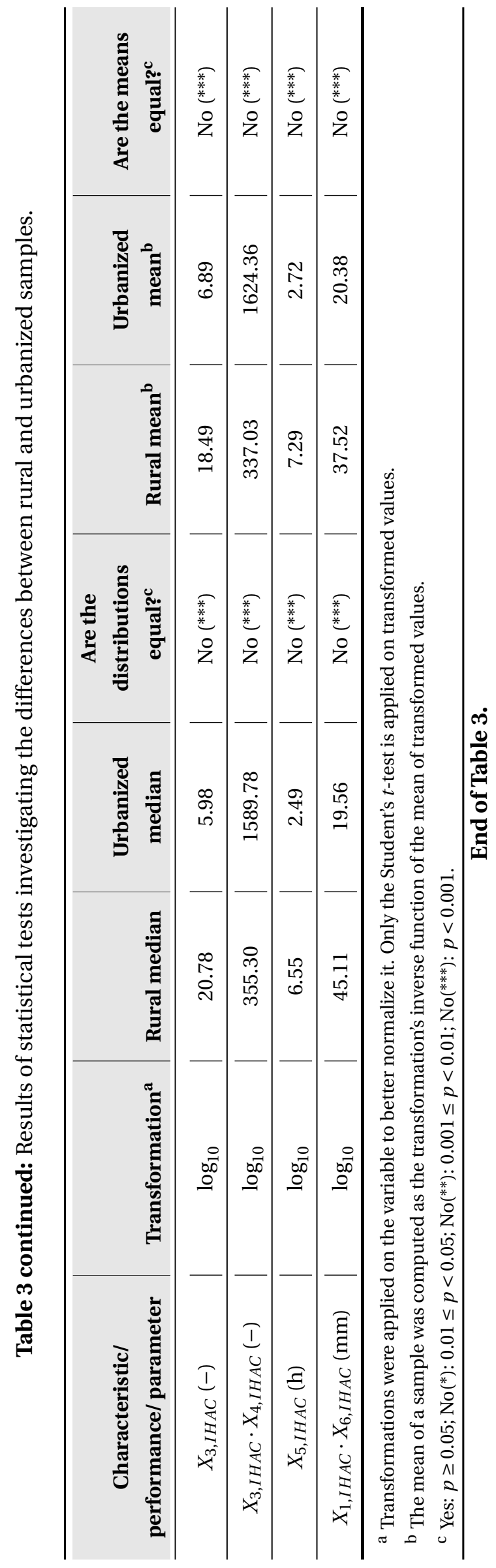




\section{References}

Addor, N., et al. 2020. "Large-sample hydrology: recent progress, guidelines for new datasets and grand challenges". Hydrological Sciences Journal 65 (5): 712-725. ISSN: 0262-6667. doi:10 . 1080 / 02626667.2019 .1683182$. Cited on page 2 .

Addor, N., et al. 2017. “The CAMELS data set: catchment attributes and meteorology for large-sample studies”. Hydrology and Earth System Sciences 21 (10): 5293-5313. ISSN: 1027-5606. doi:10 .5194/ hess-21-5293-2017. Cited on page 2.

Arnold, C. L. J., and C. J. Gibbons. 1996. "Impervious surface coverage: The emergence of a key environmental indicator". Journal of the American Planning Association 62 (2): 243-258. ISSN: 0194-4363. doi:10 . 1080 / 01944369608975688. Cited on page 3 .

Baker, D. B., et al. 2004. "A new flashiness index: Characteristics and applications to midwestern rivers and streams". JAWRA Journal of the American Water Resources Association 40 (2): 503-522. ISSN: 1752-1688. doi:10 . 1111 / j . $1752-1688.200$ 4. tb01046.x. Cited on pages 2, 6 .

Beck, H. E., et al. 2018. "Present and future Köppen-Geiger climate classification maps at 1-km resolution”. Scientific Data 5 (1): 1-12. ISSN: 2052-4463. doi:10.1038/sdata.2018.214. Cited on page 5.

Beven, K. J. 2006. "A manifesto for the equifinality thesis”. Journal of Hydrology, The model parameter estimation experiment, 320 (1): 18-36. ISSN: 0022-1694. doi:10.1016/j.jhydrol.2005.07.007. Cited on page 19.

Blume, T., E. Zehe, and A. Bronstert. 2007. "Rainfall—runoff response, event-based runoff coefficients and hydrograph separation”. Hydrological Sciences Journal 52 (5): 843-862. ISSN: 0262-6667. doi:10 . 1623 / hys j . 52 . 5 . 84 3. Cited on page 6.

Boer-Euser, T. de, et al. 2017. "Looking beyond general metrics for model comparison - lessons from an international model intercomparison study”. Hydrology and Earth System Sciences 21 (1): 423-440. ISSN: 1027-5606. doi:1 0.5194 / hes S-21423-2017. Cited on page 20.

Brabec, E., S. Schulte, and P. L. Richards. 2002. "Impervious surfaces and water quality: A review of current literature and its implications for watershed planning". Journal of Planning Literature 16 (4): 499-514. ISSN: 0885-4122. doi:10 . 1177 / 0885 41202400903563. Cited on page 3.

Braud, I., et al. 2013. "Evidence of the impact of urbanization on the hydrological regime of a medium-sized periurban catchment in France". Journal of Hydrology, Hydrology of peri-urban catchments: processes and modelling, 485:5-23. ISSN: 0022-1694. doi:10.1016/j.jhydrol.2012.04.049. Cited on page 19.

Brigode, P., L. Oudin, and C. Perrin. 2013. "Hydrological model parameter instability: A source of additional uncertainty in estimating the hydrological impacts of climate change?” Journal of Hydrology 476:410-425. ISSN: 0022-1694. doi:10 . 1016 /j.jhydrol.2012.11.012. Cited on page 20.

Brun, S. E., and L. E. Band. 2000. "Simulating runoff behavior in an urbanizing watershed". Computers, Environment and Urban Systems 24 (1): 5-22. ISSN: 0198-9715. doi:10.1016/S0198-9715 (99) 00040 -X. Cited on pages 3, 19.

Burns, D., et al. 2005. "Effects of suburban development on runoff generation in the Croton River basin, New York, USA". Journal of Hydrology 311 (1): 266-281. ISSN: 0022-1694. doi:10.1016/j. jhydrol.2005.01.022. Cited on page 19.

Chen, R.-s., W.-N. Chuang, and S.-j. Cheng. 2014. "Effects of urbanization variables on model parameters for watershed divisions". Hydrological Sciences Journal 59 (6): 1167-1183. ISSN: 0262-6667. doi:10 . 1080 / 02626667.2014 .910305$. Cited on page 2 .

Cicco, L. A. D., et al. 2018. dataRetrieval: R packages for discovering and retrieving water data available from U.S. federal hydrologic web services. Reston, VA: U.S. Geological Survey. doi:10.5066/P 9X4L3GE. Cited on page 4.

Collischonn, W., and F. M. Fan. 2013. "Defining parameters for Eckhardt's digital baseflow filter”. Hydrological Processes 27 (18): 2614-2622. ISSN: 1099-1085. doi:10.1002/ hyp. 9391. Cited on page 6.

Congedo, L., et al. 2016. "Copernicus high-resolution layers for land cover classification in Italy". Journal of Maps 12 (5): 1195-1205. doi:10.1080/17445647.2016.1145151. Cited on page 5.

DeWalle, D. R., et al. 2000. "Potential effects of climate change and urbanization on mean annual streamflow in the United States”. Water Resources Research 36 (9): 2655-2664. ISSN: 1944-7973. doi:10.1029/2000WR900134. Cited on pages 2, 17. 
Diem, J. E., T. C. Hill, and R. A. Milligan. 2018. "Diverse multi-decadal changes in streamflow within a rapidly urbanizing region”. Journal of Hydrology 556:61-71. ISSN: 0022-1694. doi:10 .1016/j . jhydrol .2017.10.026. Cited on page 17.

Dotto, C. B. S., et al. 2011. "Performance and sensitivity analysis of stormwater models using a Bayesian approach and long-term high resolution data”. Environmental Modelling \& Software 26 (10): 1225-1239. ISSN: 1364-8152. doi:10 1016 /j.envsoft.2011.03.013. Cited on page 6 .

Ebel, B. A., and K. Loague. 2006. "Physics-based hydrologic-response simulation: Seeing through the fog of equifinality". Hydrological Processes 20 (13): 2887-2900. ISSN: 1099-1085. doi:10.1002/hyp. 6388. Cited on page 19.

Eckhardt, K. 2005. "How to construct recursive digital filters for baseflow separation”. Hydrological Processes 19 (2): 507-515. ISSN: 1099-1085. doi:10.1002/hyp. 5675. Cited on page 6.

Edijatno et al. 1999. “GR3J: a daily watershed model with three free parameters”. Hydrological Sciences Journal 44 (2): $263-277$. ISSN: 0262-6667. doi:10.1080/02626669909492221. Cited on page 7.

Esse, W. R. van, et al. 2013. "The influence of conceptual model structure on model performance: a comparative study for 237 French catchments". Hydrology and Earth System Sciences 17 (10): 4227-4239. ISSN: 1027-5606. doi:10 . 5194 / hess-174227-2013. Cited on page 2.

Falcone, J. A. 2011. GAGES-II: Geospatial Attributes of Gages for Evaluating Streamflow. USGS Unnumbered Series. Reston, VA: U.S. Geological Survey. Visited on 07/23/2019. http: / pubs. er. usgs.gov/publication/70 046617 . Cited on page 4 .

Ficchì, A., C. Perrin, and V. Andréassian. 2019. "Hydrological modelling at multiple sub-daily time steps: Model improvement via flux-matching”. Journal of Hydrology 575:1308-1327. ISSN: 0022-1694. doi:10 . 1016/j . jhydrol . 2019.05.084. Cited on pages $2,6,8$.

FitzHugh, T. W., and R. M. Vogel. 2011. “The impact of dams on flood flows in the United States”. River Research and Applications 27 (10): 1192-1215. ISSN: 1535-1467. doi:10 .1002/rra.1417. Cited on page 3.

Fletcher, T. D., H. Andrieu, and P. Hamel. 2013. “Understanding, management and modelling of urban hydrology and its consequences for receiving waters: A state of the art”. Advances in Water Resources, 35th Year Anniversary Issue, 51:261-279. ISSN: 0309-1708. doi:10.1016/j . advwatres.2012.09.001. Cited on page 2.

Göbel, P., et al. 2004. "Near-natural stormwater management and its effects on the water budget and groundwater surface in urban areas taking account of the hydrogeological conditions”. Journal of Hydrology, Urban Hydrology, 299 (3): $267-283$. ISSN: 0022-1694. doi:10.1016/j.jhydrol.2004.08.013. Cited on page 17.

Gupta, H. V., et al. 2014. "Large-sample hydrology: a need to balance depth with breadth". Hydrology and Earth System Sciences 18 (2): 463-477. ISSN: 1027-5606. doi:10.5194 / hess-18-463-2014. Cited on page 2.

Gupta, H. V., et al. 2009. "Decomposition of the mean squared error and NSE performance criteria: Implications for improving hydrological modelling”. Journal of Hydrology 377 (1): 80-91. ISSN: 0022-1694. doi:10 . 1016 / j . jhydrol . 2009.08 .0 03 . Cited on page 7.

Holko, L., et al. 2011. "Flashiness of mountain streams in Slovakia and Austria”. Journal of Hydrology 405 (3): 392-401. ISSN: 0022-1694. doi:10.1016/j.jhydrol.2011.05.038. Cited on page 6.

Hollis, G. E. 1977. "Water yield changes after the urbanization of the Canon's Brook catchment, Harlow, England”. Hydrological Sciences Bulletin 22 (1): 61-75. ISSN: 0303-6936. doi:10.1080/02626667709491694. Cited on page 17.

Homer, C., et al. 2015. "Completion of the 2011 National Land Cover Database for the Conterminous United States Representing a decade of land cover change information”. Photogrammetric Engineering \& Remote Sensing 81 (5): 345-354. ISSN: 0099-1112. doi:10.1016/S0099-1112 (15) 30100-2. Cited on page 4.

Jakeman, A. J., I. G. Littlewood, and P. G. Whitehead. 1990. “Computation of the instantaneous unit hydrograph and identifiable component flows with application to two small upland catchments”. Journal of Hydrology 117 (1): 275-300. ISSN: 0022-1694. doi:10.1016/0022-1694(90)90097-H. Cited on page 6.

Klemeš, V. 1986. “Operational testing of hydrological simulation models”. Hydrological Sciences Journal 31 (1): 13-24. ISSN: 0262-6667. doi:10.1080/02626668609491024. Cited on page 7.

Lancia, M., et al. 2019. "Analysis of groundwater resources in densely populated urban watersheds with a complex tectonic setting: Shenzhen, southern China”. Hydrogeology Journal 27 (1): 183-194. ISSN: 1435-0157. doi:10.100 0 / s $10040-018-$ $1867-2$. Cited on page 17. 
Lebecherel, L., V. Andréassian, and C. Perrin. 2013. "On regionalizing the Turc-Mezentsev water balance formula". Water Resources Research 49 (11): 7508-7517. ISSN: 1944-7973. doi:10 .1002/2013WR013575. Cited on page 4.

Leleu, I., et al. 2014. "La refonte du système d'information national pour la gestion et la mise à disposition des données hydrométriques”. La Houille Blanche, no. 1: 25-32. ISSN: 0018-6368, 1958-5551. doi:10 .1051/ 1 hb/2014004. Cited on page 4.

Leopold, L. B. 1968. "Hydrology for urban land planning: A guidebook on the hydrologic effects of urban land use". Geological Survey Circular 554. Cited on page 17.

Lin, Y., and K. E. Mitchell. 2005. “The NCEP stage II/IV hourly precipitation analyses: Development and applications”. In Proceedings of the 19th conference on Hydrology, 9-13. Citeseer. Cited on page 4.

Martin, E. H., C. Kelleher, and T. Wagener. 2012. "Has urbanization changed ecological streamflow characteristics in Maine (USA)?” Hydrological Sciences Journal 57 (7): 1337-1354. ISSN: 0262-6667. doi:10 . 1080 / 02626667.2012 .707318$. Cited on pages 2, 3 .

Mathevet, T. 2005. "Quels modèles pluie-débit globaux pour le pas de temps horaire ? Développement empirique et comparaison de modèles sur un large échantillon de bassins versants”. Thèse de doctorat, ENGREF (Paris). Cited on page 8.

McIntyre, N., and M. Marshall. 2010. "Identification of rural land management signals in runoff response". Hydrological Processes 24 (24): 3521-3534. ISSN: 1099-1085. doi:10 . 1002 / hyp. 7774 . Cited on page 19.

Mei, Y., and E. N. Anagnostou. 2015. "A hydrograph separation method based on information from rainfall and runoff records". Journal of Hydrology 523:636-649. ISSN: 0022-1694. doi:10 . 1016 / j . jhydrol .2015.01 . 083. Cited on page 6.

Mejía, A. I., et al. 2015. “Anthropogenic controls from urban growth on flow regimes”. Advances in Water Resources 84:125-135. ISSN: 0309-1708. doi:10.1016/j.advwatres.2015.08.010. Cited on page 19.

Merz, R., J. Parajka, and G. Blöschl. 2011. “Time stability of catchment model parameters: Implications for climate impact analyses”. Water Resources Research 47 (2). ISSN: 1944-7973. doi:10.1029/2010WR0 0950 5. Cited on page 19.

Miller, J. D., and T. Hess. 2017. “Urbanisation impacts on storm runoff along a rural-urban gradient”. Journal of Hydrology 552:474-489. ISSN: 0022-1694. doi:10.1016/j.jhydrol.2017.06.025. Cited on pages 17, 19.

Oudin, L., et al. 2006. "Dynamic averaging of rainfall-runoff model simulations from complementary model parameterizations". Water Resources Research 42 (7). ISSN: 1944-7973. doi:10.1029/2005WR0 04636 . Cited on page 7.

Oudin, L., et al. 2018. "Hydrological impacts of urbanization at the catchment scale". Journal of Hydrology 559:774-786. ISSN: 0022-1694. doi:10.1016/j.jhydrol.2018.02.064. Cited on pages 2, 17.

Oudin, L., et al. 2005. "Which potential evapotranspiration input for a lumped rainfall-runoff model?: Part 2-Towards a simple and efficient potential evapotranspiration model for rainfall-runoff modelling”. Journal of Hydrology 303 (1): 290-306. ISSN: 0022-1694. doi:10.1016/j.jhydrol.2004.08.026. Cited on page 5.

Pathiraja, S., et al. 2018. "Time-varying parameter models for catchments with land use change: the importance of model structure”. Hydrology and Earth System Sciences 22 (5): 2903-2919. ISSN: 1027-5606. doi:10 . 5194 / hes s-22-2903-201 8. Cited on page 19.

Perrin, C. 2000. "Vers une amélioration d'un modèle global pluie-débit au travers d'une approche comparative". Thèse de doctorat, Grenoble INPG. Cited on page 8.

Perrin, C., et al. 2007. "Impact of limited streamflow data on the efficiency and the parameters of rainfall—runoff models". Hydrological Sciences Journal 52 (1): 131-151. ISSN: 0262-6667. doi:10 . 1623 / hy s j . 52 .1 .131. Cited on page 3.

Read, J. S., et al. 2015. "geoknife: Reproducible web-processing of large gridded datasets”. Ecography. doi:10 . 1111 /ecog • 0 1880. Cited on page 4.

Rodriguez, F., H. Andrieu, and F. Morena. 2008. "A distributed hydrological model for urbanized areas - Model development and application to case studies”. Journal of Hydrology 351 (3): 268-287. IssN: 0022-1694. doi:1 0 . 1016 / j . jhydrol. 200 7.12.007. Cited on page 6 .

Saadi, M., L. Oudin, and P. Ribstein. 2019. "Random forest ability in regionalizing hourly hydrological model parameters". Water 11 (8): 1540. doi:10.3390/w11081540. Cited on page 21. 
Salvadore, E., J. Bronders, and O. Batelaan. 2015. "Hydrological modelling of urbanized catchments: A review and future directions”. Journal of Hydrology 529:62-81. ISSN: 0022-1694. doi:10 . 1016 / j . jhydrol . 2015.06.028. Cited on pages $2,3,6,17$.

Santos, L., G. Thirel, and C. Perrin. 2018. “Technical note: Pitfalls in using log-transformed flows within the KGE criterion”. Hydrology and Earth System Sciences 22 (8): 4583-4591. ISSN: 1027-5606. doi:10 . 5194/hess-22-4583-2018. Cited on page 7.

Sanzana, P., et al. 2019. "Impact of urban growth and high residential irrigation on streamflow and groundwater levels in a peri-urban semiarid catchment". JAWRA Journal of the American Water Resources Association 55 (3): 720-739. ISSN: 1752-1688. doi:10.1111/1752-1688.12743. Cited on page 17

Seibert, J., and J. J. McDonnell. 2010. "Land-cover impacts on streamflow: a change-detection modelling approach that incorporates parameter uncertainty”. Hydrological Sciences Journal 55 (3): 316-332. ISSN: 0262-6667. doi:1 0 . 1080 / 0262 6661003683264 . Cited on page 19.

Sillanpää, N., and H. Koivusalo. 2015. "Impacts of urban development on runoff event characteristics and unit hydrographs across warm and cold seasons in high latitudes”. Journal of Hydrology 521:328-340. ISSN: 0022-1694. doi:10 . $1016 / j$. jh ydrol.2014.12.008. Cited on page 17

Tabary, P., et al. 2012. “A 10-year (1997-2006) reanalysis of Quantitative Precipitation Estimation over France: methodology and first results". IAHS Publication 351:255-260. Cited on page 4.

Thornton, P. E., et al. 2016. "Daymet: Daily surface weather data on a 1-km grid for North America, version 3". ORNL DAAC. doi:10.3334/ORNLDAAC/1328. Cited on page 4.

Van Loon, A. F., et al. 2019. "Using paired catchments to quantify the human influence on hydrological droughts". Hydrology and Earth System Sciences 23 (3): 1725-1739. ISSN: 1027-5606. doi:10.5194 / hess-23-1725-2019. Cited on page 3.

Vidal, J.-P., et al. 2010. “A 50-year high-resolution atmospheric reanalysis over France with the Safran system”. International Journal of Climatology 30 (11): 1627-1644. ISSN: 1097-0088. doi:10 . 1002 / joc . 2003 . Cited on page 5.

Zégre, N., et al. 2010. "In lieu of the paired catchment approach: Hydrologic model change detection at the catchment scale". Water Resources Research 46 (11). ISSN: 1944-7973. doi:10.1029/2009WR008601. Cited on page 3.

Zektser, I. S., and L. G. Everett. 2004. Groundwater resources of the world and their use. Vol. IHP-VI, Series on Groundwater No. 6. Paris, France: UNESCO. ISBN: 978-92-9220-007-7. Cited on page 19.

Zhou, Z., et al. 2017. "The complexities of urban flood response: Flood frequency analyses for the Charlotte metropolitan region”. Water Resources Research 53 (8): 7401-7425. ISSN: 1944-7973. doi:10 .1002/2016WR019997. Cited on page 17. 
